\title{
Assessing the performances of elastic-plastic buckling and shell-solid combination in finite element analysis on plated structures with and without idealised corrosion defects
}

\author{
Y. Wang ${ }^{1,2}$, J. Downes ${ }^{1,2}$, J.A. Wharton ${ }^{3}$ and R.A. Shenoi ${ }^{1,2}$ \\ 1. Fluid Structure Interactions Group, University of Southampton, Southampton, UK \\ 2. Southampton Marine and Maritime Institute, University of Southampton, Southampton, UK \\ 3. National Centre of Advanced Tribology at Southampton, University of Southampton, Southampton, \\ UK
}

\begin{abstract}
Ships and offshore structures operate in harsh and corrosive environments and they are subject to high hydrodynamic and inertial loads. Thus it is important to accurately predict the mechanical response of thin-walled marine structures subject to corrosion damage in loaded conditions. This paper present a transition study to investigate in depth the usage of shell and solid elements in nonlinear finite element structural analysis with localised corrosion features. An experimental, stereo full field imaging technique, 3D digital image correlation is used to verify both the shell and solid modelling results. The solid-to-shell coupling techniques were subsequently assessed based on a deck plate model. Models containing a localised section using either the second-order hexahedral element C3D20 or tetrahedral element C3D10I show a similar performance that is compatible with the model using only shell element. The proposed coupling method works well for localised electrochemical or mechanical-electrochemical analysis with subsequent geometrical updates.
\end{abstract}

Keywords: finite element method; digital image correlation; buckling; model coupling; corrosion.

\section{Nomenclature}

a Length of the deck plate model / $\mathrm{mm}$

$b \quad$ Width of the deck plate model / $\mathrm{mm}$

C Correlation function

$d_{\mathrm{p}} \quad$ Position tolerance for the surface-based approach / $\mathrm{mm}$

$\boldsymbol{e}_{i} \quad$ Current configuration base vector (regardless of rotation constraint at the slave node)

E Young's modulus / GPa

$F \quad$ Grey value matrix of reference image

$\boldsymbol{F}^{\text {Shell }}$ Force distribution at the reference shell node

$F_{i}^{\text {Solid }} \quad$ Force distribution at the coupling solid node $i$

$G \quad$ Grey value matrix of deformed image

I Second-order identity tensor

$k \quad$ Smallest integral satisfying $a / b \leq \sqrt{k(k+1)}$

$m \quad$ Pixel location in the reference image

$\boldsymbol{M}^{\text {Shell }}$ Moment at the reference shell node

$n \quad$ Pixel location in the reference image

$\boldsymbol{n} \quad$ Normal direction of the deformed solid configuration

$N \quad$ Subset size

$\boldsymbol{N} \quad$ Normal direction of the reference solid configuration

$\boldsymbol{r}_{\mathrm{i}} \quad$ Influence distance at the coupling solid node $i$ for the surface-based approach / $\mathrm{mm}$ 
$\boldsymbol{R}\left(\boldsymbol{\phi}^{\mathrm{m}}\right)$ Rotation matrix associated with the master node rotation $\boldsymbol{\phi}^{\mathrm{m}}$

$\boldsymbol{S} \quad$ Skew symmetric matrix form of the rotation vector $\boldsymbol{\phi}$

$t_{\mathrm{p}} \quad$ Thickness of the deck plate model / $\mathrm{mm}$

$\boldsymbol{T} \quad$ Coupling node arrangement inertia tensor

$u \quad$ Displacement of the subset centre from the reference image to the deformed image / $\mathrm{mm}$

$\boldsymbol{u}^{\text {Shell }}$ Displacement of the shell node

$\boldsymbol{u}_{i}^{\text {Solid }}$ Displacement of the solid node $i$

$v \quad$ Displacement of the subset centre from the reference image to the deformed image / $\mathrm{mm}$

$w_{i} \quad$ Weighing factor at solid node $i$

$\bar{w}_{\mathrm{i}} \quad$ Nominalised weight factor

$w_{\mathrm{p}} \quad$ Deck plate initial deflection

$\boldsymbol{x}^{\mathrm{m}} \quad$ Deformed configuration position of master node

$\overline{\boldsymbol{x}}^{\mathrm{s}} \quad$ Fully constrained slave node position

$\boldsymbol{x}^{\mathrm{s}} \quad$ Partially constrained slave node position

$x^{\text {Shell }}$ Positions of the reference shell node

$\boldsymbol{x}_{\mathrm{i}}^{\text {Solid }}$ Positions of the coupling solid node $i$

$\boldsymbol{X}^{\mathrm{s}} \quad$ Reference configuration positions of the slave node

$\boldsymbol{X}^{\mathrm{m}} \quad$ Reference configuration positions of the master node

$y_{i} \quad$ Translation degree of freedom $i$ at the additional node $/ \mathrm{mm}$

$\begin{array}{ll}\beta & \text { Slenderness ratio } \\ v & \text { Poisson ratio } \\ \sigma_{\mathrm{y}} & \text { Yield stress of the material / MPa } \\ \phi & \text { Rotation vector } \\ \boldsymbol{\phi}^{\mathrm{m}} & \text { Master node rotation }\end{array}$

\section{Introduction}

Corrosion damage accumulation in association with thin-walled structural resilience in marine environments has been an area of study over the last few decades [1-3]. The accuracy of the structural analysis can directly affect reliability prediction and maintenance or repair strategies [4]. Depending on the structural location, material properties, and the service environment, corrosion damage either can spread over the entire plating, become localised in regions that are associated with a failed protection system (i.e., polymeric coating defects or cathodic protection problems) or be linked to complex geometrical surfaces including weld imperfections. Figure 1 shows an example of such an imperfection along a butt weld. Rough surfaces due to corrosion and rust can be potential stress concentration sites and thus a threat to structural reliability [5-7]. To assess these corrosion effects, numerous studies have been undertaken on plated or tubular marine structures containing representative corrosion features [3, 8-14]. Among the limited analysis approaches, the finite element method with fully nonlinear material and geometric properties is commonly used to predict ultimate strength capacity primarily for small scale or individual structural members with corrosion damage. Many finite element analysis (FEA) models use a two-dimensional (2D) 4-node shell element to simulate structures which require modelling of sections of plating, box girders and hull girders. In these scenarios, the corrosion damage is normally idealised as a uniform thickness reduction especially for hull girder and platform simulations [15-19]. Smaller models with local 
thickness variations have also been studied where different section properties need to be assigned to shell elements $[3,10,20]$. Verifications by both laboratory and practical experience have shown that under appropriate boundary conditions and hourglass control, shell elements are capable of accurately predicting the ultimate strength of intact plated structures at low computational cost and with less modelling effort [4, 8, 21, 22]. In comparison, models built by either three-dimensional (3D) solid elements show an enhanced ability to simulate more realistic corrosion topographies [6, 23]. Surface mapping tools can be used to transfer actual corroded surface features directly to a $3 \mathrm{D}$ model [9, 23-25]. Therefore, detailed stress and strain distributions can be obtained for the surface. However, shear and volume locking may occur in such models that prevent thin-walled structure behaviour. The high computational cost also indicates that it is almost impossible to use solid models for rapid strength prediction of ship hulls or offshore platforms practically [26, 27].

Alternatively, for marine structures with 15 to 20 years of operational service, the accumulation and evolution of corrosion damage will result in progressive changes in structural geometry and hence influence strength capacity. There is sufficient evidence to indicate a clear interplay between corrosion and stress / strain distributions for mechanically loaded surfaces [28-30]. Under these situations, corrosion may be significantly accelerated resulting in a so-called mechanically-assisted corrosion [30-32]. Theoretical and laboratory investigations have aimed to understand this mechanical -electrochemical corrosion behaviour [33-36]. Recently, the authors have also conducted a series of in situ tests and obtained corrosion data for shipping grade carbon steels under tensile stress [37] which showed a clear dependence of the corrosion kinetics on tensile stresses. However, such corrosion data can only be utilised effectively on actual marine structures if the stress and strain predictions are reliable, especially for surfaces with complex geometrical features. To date, only a few small-scale numerical studies are available in the open literature simulating long-term corrosion degradation from the electrochemical or mechanical-electrochemical standpoint, with no further corresponding structural performance assessment [37-39]. Nearly all large-scale structural analysis that considers the influence of corrosion with time use statistical models and field / survey data [40,41]. Although these databases may contain the holistic effects for a range of corrosion factors, the lack of an up-to-date database and insufficient data quantity can result in unrealistic damage prediction. Moreover, the effect of localised corrosion damage on the overall structural performance is not sufficiently understood at the appropriate spatial and temporal scales necessary.

Therefore, there is a drive to develop an interactive corrosion-structure modelling strategy where electrochemical or mechanical-electrochemical theories and laboratory data can be implemented, i.e., the model is capable of accurately predicting the detailed stress / strain distributions on the structural surface with corrosion. The developed model should also be computationally economical for large-scale analysis so as to enable implementation into standard structural modelling practices. This paper presents a transition study, in addition to the authors' corrosion experimental work [37], towards the corrosion-structure model development for aging ships and offshore platforms.

Firstly, to guarantee the reliability of the FEA models, a novel stereo full field imaging experimental technique, namely digital image correlation (DIC), is used to validate the numerical method. Due to the geometric complexity of the corrosion damage, identifying the early stress/strain concentrations around the defect are of great importance when assessing the structural resilience. However, Fto date, most of this information is obtained by numerical studies. For elastic-plastic buckling scenarios, the validation of such numerical models are often carried out by simply comparing the loadshortening curves to experiments. there-There is little full-field experimental work available in the 
literature assessing the elastic-plastic buckling of a steel plate with defects. As a result, most numerical model validation is done by comparing the load-shortening curves. However, forvalidating the surface stress and/or strain on an uneven surfaces there is a need to validate the stress or strain distribution/concentration as well. The DIC study in this paper fills the gap by providing physical evidence of strain and displacement distributions on the specimen surface with various local damage. Secondly, localised corrosion is increasingly more of a concern for aging ships and offshore structures, therefore this work proposes to combine a detailed local corrosion model (preferably using solid elements) with a global shell model. Although there are several existing models with a mixture of shell and solid elements [25, 42, 43], the connection at the interface and the actual modelling technique were not explicitly stated. In the current study, the shell-to-solid constraining techniques are thoroughly assessed based on a simply supported deck plate model.

\section{Methodology}

\section{Digital Image Correlation (DIC)}

DIC enables a full field measurement of deformation and displacement and has been successfully utilised in monitoring crack propagations and large plastic deformation of various materials [44-48]. The concept is to evaluate the object deformation by tracking deformation of a random pattern in an image. Each pixel within an image has a grey value. DIC applies a stochastic speckle pattern to provide unique information of a small aperture (subset or interrogation cell) for pattern matching on the specimen surface. The motion estimation method is based on minimising the squared difference in grey values, namely a summation of squares deviation. The correlation function is expressed as follows [49]:

$$
C(m, n, u, v)=\sum_{i, j=-N / 2}^{N / 2}[G(m+u+i, n+v+j)-F(m+i, n+j)]^{2}
$$

where $m$ and $n$ denote the pixel location in the reference image; $u$ and $v$ represent the displacements of the subset centre from the reference (undeformed) image to the deformed image; $N$ is the size of the subset; $G$ and $F$ are the grey value matrices of deformed and reference images, respectively. More detailed DIC information can be found in Ref [49].

For the current study LaVision DaVis 8.1.0 correlation software was adopted employing the least square method to iteratively approximate the deformation [50]. The iteration starts from the selected seeding point(s) and the analysed region grows with the existing information utilised as a predictor for a possible match. After identifying all subsets in the deformed image, the displacement data can be converted to Lagrangian strain tensor or engineering strain for the area of interest. Once the surface deformations are obtained, DaVis uses a central difference scheme to compute the strain values [50]. A single charge-coupled device (CCD) camera cannot distinguish uniform strain from uniform out-of-plane displacement [51]. By using a two-camera stereo set-up (3D DIC), the calibration process helps build a 'working volume' and informs the positions of the two cameras relative to each other [52] to calculate the out-of-plane deformation.

The present study used a servo-hydraulic test machine Instron 8032 to apply quasi-static uniaxial compressive loading by displacement control $\left(1 \mathrm{~mm} \mathrm{~min}^{-1}\right)$. The specimen weight and the test jig 
were balanced out prior to external loading. The experimental set-up is shown in Figure 2. Two 5 megapixel 12-bit monochromatic LaVision E-lite CCD cameras were used with two Sigma 105 lenses (Figure $2 \mathrm{~b}$ ). The cameras were positioned with viewing directions $30^{\circ}$ relative to each other in front of the specimen. A floodlight was used to enhance the illumination. The deformation was recorded at a frequency of $1 \mathrm{~Hz}$, including the load and displacement provided by the Instron machine. Steel jigs were designed specifically for such thin wide column compressive tests, as shown in Figure 2a, where the two lubricated pillars were press fit at the bottom and free slide at the top, in order to achieve a uniform in-plane compressive stress. Specimen surface finish consisted of a matt black paint with white speckles. The average speckle size was five pixels across and the spatial resolution was 24.4 pixels $\mathrm{mm}^{-1}$.

Four DIC specimens were fabricated from Grade $070 \mathrm{M} 20$ steel with dimensions: $110 \mathrm{~mm} \times 90 \mathrm{~mm}$ $\times 3 \mathrm{~mm}$ (actual test area: $90 \mathrm{~mm} \times 90 \mathrm{~mm}$ ); and four one-side idealised corrosion patterns shown in Figure 3. Before commencing the buckling tests, the initial deflections of all specimens were measured using an Aberlink 3D Faro Arm (single point $0.01 \mathrm{~mm}$ ) at discrete locations across the specimen surface. The measured initial deflections for the four corrosion patterns are shown in Figure 4. Both top and bottom edges of the specimen were clamped to the specifically designed jigs. The damage area was $15 \%$ and depth was $1.25 \mathrm{~mm}$ for all DIC specimens. A compressive load was applied quasi-statically at $1 \mathrm{~mm} \mathrm{~min}^{-1}$ with the entire loading procedure monitored by a stereo camera system at $1 \mathrm{~Hz}$ in order to capture the ultimate strength point. For data processing, the subset size was set to be $61 \times 61$ pixels while the step size (grid spacing) was 19 pixels, leading to a $31 \%$ overlap. The correlation mode was set to be the sum of differential of the preceding images, which is suitable for large deformation over time. Since the test jig experienced elastic deformations during the loading process, strain values instead of displacement along the load direction were examined.

\section{Coupling shell and solid model techniques}

The commercial FEA package Abaqus is a popular tool in both research and industry for performing structural analysis due to its robust nonlinear solver and versatility via command lines and Python scripting. However, little information or study is available in the open literature showing the software performance when combining shell and solid elements. In a combined shell-solid model, the transition from a shell edge to a multi-layered solid cross-section can be achieved by using either constraint formulations or a sub-modelling technique. Particularly, three types of constraint methods are available: (i) multi-point constraints (MPC), (ii) kinematic coupling and (iii) surfacebased shell-to-solid coupling constraint. The MPC in combination with the SLIDER constraint (SS LINEAR, SS BILINEAR, SSF BILINEAR) enforces the same displacement and compatible rotation at the shell and solid interface while maintaining straight lines through the solid thickness. Weighting functions were used for the solid nodes through thickness [53]:

$$
\boldsymbol{u}^{\text {Shell }}=\sum_{i=1}^{n} w_{i} \boldsymbol{u}_{i}^{\text {Solid }}
$$

where $\boldsymbol{u}^{\text {Shell }}$ is the displacement of the shell node; $\boldsymbol{u}_{i}^{\text {Solid }}$ is the displacement of the solid node; $w_{i}$ is the weighing factor based on the MPC type and solid nodal locations. The shell-to-solid MPC needs to be defined individually at each node along the shell facets. Moreover, the lines of throughthickness solid nodes need to be preferably aligned with shell nodes, which limits the flexibility of meshing the solid model. 
Kinematic coupling constraints the degrees of freedom (DOFs) of a set of slave nodes to a master node by creating an additional node internally for each slave node. For a fully constrained slave node, the displacement and rotations are calculated as follows [53]:

$$
\boldsymbol{R}\left(\boldsymbol{\phi}^{\mathrm{m}}\right) \cdot\left(\boldsymbol{X}^{\mathrm{s}}-\boldsymbol{X}^{\mathrm{m}}\right)=\overline{\boldsymbol{x}}^{\mathrm{s}}-\boldsymbol{x}^{\mathrm{m}}
$$

where $\boldsymbol{X}^{\mathrm{s}}$ and $\boldsymbol{X}^{\mathrm{m}}$ are the reference configuration positions of the slave node and master node respectively; $\overline{\boldsymbol{x}}^{\mathrm{s}}$ is the fully constrained slave node position in the current configuration; $\boldsymbol{x}^{\mathrm{m}}$ is the current configuration position of the master node; and $\boldsymbol{R}\left(\boldsymbol{\phi}^{\mathrm{m}}\right)$ is the rotation matrix associated with the master node rotation $\phi^{\mathrm{m}}$. Partially constrained slave node position can be calculated by adding a DOF term to $\overline{\boldsymbol{x}}^{\mathrm{s}}$.

However, this method does not enforce the straightness of the through-thickness lines, and hence does not comply with either Kirchhoff or Mindlin shell theories. It is also difficult to define the actual control area on solid cross-sections.

In comparison to the two node-based constrain methods, the surface-based approach minimises numerical noise at the shell-solid interface where mismatched meshes exist. The internally distributed constraints couple the DOFs of each shell surface (edge facets) to the average DOFs of the solid surface (node- or element-based). A position tolerance $d_{\mathrm{p}}$ is used to determine the shell nodes that act as reference nodes, while within an influence distance $\boldsymbol{r}_{\mathrm{i}}$ normal from the shell edge, the node or element facet on the solid surface will be included in the coupling constraint. The force distributions satisfies:

$$
\begin{gathered}
\sum \boldsymbol{F}_{\mathrm{i}}^{\text {Solid }}=\boldsymbol{F}^{\text {Shell }} \\
\sum \boldsymbol{x}_{\mathrm{i}}^{\text {Solid }} \times \boldsymbol{F}_{i}^{\text {Solid }}=\boldsymbol{M}^{\text {Shell }}+\boldsymbol{x}^{\text {Shell }} \times \boldsymbol{F}^{\text {Shell }}
\end{gathered}
$$

where $\boldsymbol{x}_{\mathrm{i}}^{\text {Solid }}$ and $\boldsymbol{x}^{\text {Shell }}$ are positions of the coupling nodes and reference node respectively; load $\boldsymbol{F}^{\text {Shell }}$ and moment $\boldsymbol{M}^{\text {Shell }}$ are at the reference node; and $\boldsymbol{F}_{i}^{\text {Solid }}$ is the force distribution at coupling node $i$. Similar to the MPC constraint, a distributing weight factor $w_{i}$ is assigned at each solid node. The linear motion of the reference node is compatible with the averaged coupling group motion, which results in a linearised constraint between the reference node and coupling nodes. More detailed formulations can be found in Ref. [53].

The sub-modelling technique is another option to link a global shell model and a local solid submodel. Any time-dependent results at the interface are interpolated from the global model to the submodel [53]. However, it is only suitable when the submodel performance has a negligible effect on the global solution. To reveal the influence of corrosion damage on the overall structural response, as well as to obtain more detailed stress / strain results at the damaged region, the surface-based shell to solid coupling approach was chosen in this study, for its transition of weighed forces / moments and relatively low computational effort. Both element- and node-based solid surfaces were examined. The position tolerance $d_{\mathrm{p}}$ when using an element-based solid surface was $5 \%$ of the length of the coupling facet on the shell edge [53]. When using a node-based solid surface, $d_{\mathrm{p}}$ is based on the average distance between nodes on the solid surface. The value of the influence radius $\boldsymbol{r}_{\mathrm{i}}$ for an edge facet was half the thickness of the underlying shell element. 


\section{DIC and shell-solid models}

In addition to the shell-solid models, the DIC specimens were also analysed numerically. For the DIC model, the geometry was the same as used in the experiments. Both the top and bottom edges were clamped with a uniaxial compressive displacement applied at the bottom edge. To facilitate the modelling process for comparison, surface fittings were performed using the Faro Arm mapping data to obtain a polynomial function ( $R^{2}$ values are above 0.95$)$, based on which the nodal location was updated to generate a realistic initial deflection. After the application of initial deflection using polynomial functions, both the loaded edges were straightened and the deflections were updated accordingly. The shell-solid model is based on a Panamax class tanker deck plate with dimensions of $3900 \mathrm{~mm} \times 830 \mathrm{~mm} \times 8 \mathrm{~mm}$ [15]. The boundary condition was simply supported along the four edges for the shell-solid model, as illustrated in Figure 5. A Fourier form of initial deflection $w_{\mathrm{p}}$ (Eq. 6) was applied to the plate, which is suggested by Smith et al. [54].

$$
w_{\mathrm{p}}=0.1 \beta^{2} t_{\mathrm{p}} \sin \left(\frac{k \pi x}{a}\right) \sin \left(\frac{\pi y}{b}\right)
$$

where $\beta=b / t_{\mathrm{p}} \sqrt{\sigma_{\mathrm{y}} / E}$ is the slenderness ratio; $a$ is the length of the plate; $b$ is the width of the plate; $t_{\mathrm{p}}$ is the thickness of the plate; $\sigma_{\mathrm{y}}$ is the yield stress of the material; $k$ is the smallest integral satisfying $a / b \leq \sqrt{k(k+1)}$, which is equal to 5 for the current model geometry. The stress-strain relationship of the DIC specimens are shown in Figure 6 from standard tensile tests. It can be seen that the tested steel shows little strain hardening behaviour. Therefore, for simplicity, an elasticperfectly-plastic constitutive model was assigned for the DIC columns. Similar constitutive model was also used for the deck plates from a conservative point of view. All material properties are listed in Table 1.

A nonlinear buckling analysis assesses the stability characteristics of a structure. To obtain the ultimate strength point or critical buckling load, there are main two quasi-static analysis methods, namely Newton-Raphson (NR) algorithm and Riks algorithm (arc length method). The time dependent NR method has a quadratic convergence rate and applies adaptive bisections when convergence difficulty occurs. However, when the post-buckling path is unstable with much increased deformation, divergence is inevitable no matter how small the substep size is. In comparison, the Riks method uses an extra constraint and allows a convergence at lower applied load. The load during one-step is always proportional to the current load magnitude. Due to the ability to handle both stable and unstable post-buckling behaviour, which is difficult to predict prior to an analysis especially when corrosion damage presents, all models were solved using the Riks algorithm [55]. Linear shell element with hourglass control is a common choice for thin-walled marine structural analysis due to its flexibility and low computational cost $[4,21,56]$. Therefore, the quadrilateral shell element S4R with reduced integration and enhanced hourglass control [53] was primarily chosen here to construct the DIC and the global shell models. At the damaged area with reduced thickness, the shell section was defined separately and the reference plane was offset. Five integration points were used for each shell cross-section. Based on mesh convergence studies (example shown in Figure 7a), the element size ranged between $0.7 \mathrm{~mm}$ and $3.0 \mathrm{~mm}$ for the DIC model. The mesh patterns used for DIC models are shown in Figure 3. For the deck plate model, the typical element size was $40 \mathrm{~mm}$, which showed a decreased stiffness in the post-buckling region in Figure $7 \mathrm{~b}$. It is interesting to note that there is a slight change in the ultimate stress at the finest mesh $(10 \mathrm{~mm})$. This is considered to be due to that the characteristic length of the shell element used is almost equal to the thickness of the deck plate $(8 \mathrm{~mm})$. Although there is no theoretical limit 
on the element size relative to thickness, for S4R element, the thick shell theory is used when the shell thickness increases. For elastic-plastic buckling analysis, when all shell elements are no longer "thin-walled" (characteristic element length is much larger than thickness), the global behaviour of the plate is changed, which produces a less physically accurate result compared to the four data points at a mesh size of 20 to $80 \mathrm{~mm}$.

For the local 3D section shown in Figure 5 aiming for a greater geometrical detail, hexahedral and tetrahedral elements were considered. The dimension of the 3D model was $0.3 \mathrm{~m} \times 0.3 \mathrm{~m} \times 0.008$ $\mathrm{m}$. In general, a hexahedral element has a better convergence rate than a tetrahedral element. However, the latter is less sensitive to the initial element shape, and hence could be more suitable for simulating a corroded topography [53]. Therefore, the studied elements included first-order hexahedral C3D8R with reduced integration to avoid volume / shear locking, C3D8R with enhanced hourglass formulation, second-order hexahedral C3D20 and C3D20R with full and reduced integration respectively and second-order tetrahedral elements C3D10I and C3D10. Specifically, the C3D10l has ten integration points of locations coincide with the nodes and one in the centre of the element, which improves the surface stress visualisation. Shear locking is also avoided for this element type. Typical solid element size is similar to the shell model, with four layers through thickness. Three locations of the local solid model were examined, as illustrated in Figure 5.

\section{Results and discussion}

\section{DIC experiments and models}

Figure 8 shows the average stress-strain relationships for all specimens from the DIC and FEA. It can be seen that the shell models give a good prediction up to the ultimate strength. The FEA ultimate strengths are higher than the DIC results, ranging from 3.9\% (corrosion at the corner) to $11.8 \%$ (corrosion on the unloaded edge). In the post-buckling region, FEA appears to underestimate the stress compared to the experimental results, as seen in Figure 8. The specimen manufacture is considered as the main source of discrepancy between DIC and FEA. Firstly, initial deflections were induced by machine marks and measured on a coarse grid on the specimens ( $10 \times 10$ data points) due to the limitation of the Faro Arm resolution. Although the polynomial functions show a good fitting $\left(R^{2}>0.95\right)$, some local variation around the defect were not included. Secondly, the clamped boundary condition was achieved on a $90 \mathrm{~mm} \times 10 \mathrm{~mm}$ region using a steel strip and four M6 bolts on each side (Figure 9). Since the model did not include the rigs that clamped the top and bottom edges of the specimen, the induced pre-loading to the specimen was not taken into account, and therefore led to a higher ultimate strength and lower unloading path $[9,21]$. Detailed investigation of the pre-stress effect was discussed in the authors' previous work [9]. Thirdly, the milling of the defects on the specimen surfaces may introduce a small amount of initial stresses, which could contribute to the discrepancies between experimental and FEA results.

When examining deformation and strain distributions at the ultimate strength point, the FEA show good agreement with DIC when capturing various failure modes depending on the location of the corrosion damage. Figure 10 shows examples of the FEA and DIC contour plots for a random corrosion pitting condition. By keeping the same average stress in the post-buckling region, again similar out-of-plane deformation and in-plane strain distributions were obtained from DIC and FEA. Figure 11 is an example of the specimen with random pitting damage when the reaction force is 70 
$\mathrm{kN}(260 \mathrm{MPa})$ in the post-buckling region, as indicated in Figure 8c. Visually, the out-of-plane deformation results (Figures 11a and 11b) are consistent in terms of distribution and magnitude. The in-plane strain in the loading direction also show a similar distribution from both techniques. However, discrepancies (Figures $11 \mathrm{c}$ and $11 \mathrm{~d}$ ) around the pitting edges increase compared to the ultimate strength stage (Figure 10c and 10d). Although seeding points were carefully selected around the defect edges (thickness discontinuity), there are still some regions that the DIC failed to correlate, for example the red squares in Figures 10a and 11a. The smaller subset size $(41 \times 41$ pixels) was tested resulting in limited improvement in the correlation area. In terms of strain maps, DIC achieves a high strain resolution (in the order of $10^{-3}$ ). However, noise can be seen since strain values were calculated based on the displacement results for DIC. Moreover, strains that are unrealistically high in magnitude were obtained around the defect. This is due to the discontinuous deformation inside and outside of the defect. In DIC, the deformation discontinuity around the defect edge is averaged for calculating strains, and hence could result in unrealistic strain values. Overall, the nonlinear FEA models using shell elements have been successfully verified using the DIC method. However, the buckling mode of the specimens is largely dependent on the initial state (geometric imperfection and initial stress) which may be difficult to accurately simulate.

The tetrahedral solid element C3D10I was also used to construct the DIC models. Figure 12 shows an example of the comparison results for the random pitting specimen. It is evident that the average compressive stress-strain curves obtained from the solid model is almost identical to the shell result. Similar von Mises stress distributions were obtained at ultimate strength for both models (Figure 12b and 12c). Nevertheless, examining the local stress values in detail, a non-real stress discontinuity can be found around the defect edges when connecting two shell facets with different section features. Moreover, depending on the method deployed, a range of results could be obtained for the same stress component on the same element, especially at the shared mid-plane nodes. Although the stress discontinuity in the pit using shell element has little influence on the overall structural behaviour (ultimate strength and load-shortening curves), corrosion experiments [28-30, 33-36] have shown that these areas are key for reducing rust layer integrity and potential corrosion acceleration, which may subsequently lead to cracking and change the corrosion appearance. Inconsistency of the shell normals will cause difficulty in obtaining the top and bottom surface stresses and strains. In comparison, the solid model shows a more realistic stress distribution at geometrical discontinuities, which again proves that although shell model is able to predict the overall ultimate strength capacity, local hot spot stresses are more readily accessible from solid elements. Therefore, to continuously update the structural thickness and the surface stress / strain, solid elements are considered to be a better option in the authors' future work.

\section{$\underline{\text { Shell-solid deck plate models }}$}

The deck plate model of the dimensions given in Table 1 was first constructed using only either shell or solid elements. To achieve the simply supported boundary condition, displacement constraints were applied at the mid-thickness on the solid models. Figure 13 shows the average compressive stress-strain curves from one shell element (S4R with and without enhanced hourglass control) and three solid elements (C3D8R and C3D8R with enhanced hourglass control, C3D20 with and without reduced integration and C3D10 with and without improved stress visualisation). In particular, the C3D8R model deviates from the rest of the result from the onset of loading. Due to the reduced integration with only one integration point, the locking problem is avoid in C3D8R. However, without the enhanced hourglass control, the element is overly stiff compared to the shell model. The von Mises stress distribution also shows stress discontinuity on both sides of the plate (Figure 
13). Conversely, the 20-node solid element C3D20R with reduced integration estimates a lower stress level both in the elastic and plastic buckling regions. An obvious hourglass mode can be observed at the constrained boundaries (Figure 13). The rest of the elements all present similar stress-strain curves and ultimate strength values, apart from the C3D10 model where the loss of stiffness occurs at a larger compressive deformation / strain. Therefore, based on the experimental results from the previous section, elements C3D8R with enhanced hourglass control, C3D20, C3D10 and C3D10I are potentially valid for thin-walled nonlinear buckling analysis.

Figure 14 compares the shell-solid coupling results between node-based and element-based solid interfaces for Location 1 (Figure 5). All element-based stress-strain curves are close to the one obtained from the shell model, with approximately $1 \%$ lower ultimate strength value. Post-buckling performance from C3D8R shell-solid element-based model shows an improved estimate than the node-based approach. There was little difference between the element- and node-based C3D20 models up to the post-buckling region (large deformation and rotation), due to the higher density of nodes compare to the linear elements. However, the node-based C3D10 and C3D10I models significantly underestimate the ultimate strength and strain, indicating that the second-order tetrahedral elements are more sensitive to the coupling node selection, especially under large deformation. For models with element-based solid surface, the failure modes are similar to the shell model.

Figure 15 shows the out-of-plane displacement and von Mises stress at mid-width in y-direction at the model's ultimate strength. In comparison with the shell model, the C3D20 and C3D10I models show similar displacements, whereas C3D10 and C3D8R over- and underestimate the maximum deformation, respectively (Figure 15a). For the shell-solid coupling models, all solid elements give close estimate to the shell model results. In Figure 15b, the von Mises stresses were obtained by averaging extrapolated corresponding element results when the difference between two elements is within 75\%, which leads to nosier data especially for C3D10 and C3D10I. All solid coupling models predict a similar stress distribution as the shell result. However, the model built only using C3D10 over predicts stress. The local results also corresponds with the global stress-strain relationships presented in Figures 13 and 14. It is therefore considered that the tetrahedral element performance is more affected by the simply supported boundary condition. In the shell-solid coupling scenario, the constraints along the shell edge facets lead to a more stable solid element behaviour. Figure 16 are the average stress-strain curves derived for Locations 2 and 3 (Figure 5) using element-based

solid surfaces. Depending on the assigned initial deflection, different locations would results in the solid section with different buckling shape and magnitude (Figure 17). However, the element-based shell-solid coupling method is able to provide a good estimate compared to the shell model regardless of the solid model location.

\section{Conclusion}

This paper presents a comparison between full field experimental measurement and FEA modelling regarding the elastic-plastic buckling scenario. It also explores the performances of a range of shell and solid elements and the feasibility of shell-solid coupling models in an FEA thin-walled structural analysis for both intact and damaged surfaces. Main findings are as follows: 
- The 3D DIC experimental technique on partially damaged steel specimens shows a great potential in assessing quasi-static buckling failure stress/strain and providing a full field failure mode measurements;

- A good agreement has been achieved between the DIC and FEA results in capturing the nonlinear buckling process and the local displacement/strain discontinuity around the artificial pitting damage;

- For both global and local models, the second-order hexahedral element and tetrahedral element result in consistent behaviour that is compatible with a shell model in terms of failure mode and stress distribution;

- The second-order tetrahedral elements are more sensitive to the coupling node selection, especially under large deformation;

- The shell-solid coupling method should be capable of transferring both displacement and force/moment at the shell-solid interface to provide good estimate compare to the shell model regardless of the solid model location.

Based on the current interactive corrosion-structure modelling strategy and validation, this enables reliable stress and strain predictions especially for structures with geometric complexities, which would be beneficial for effective implementation of experimental corrosion data for localised electrochemical or mechanical-electrochemical analysis. Future work will be conducted to investigate the effects of other boundary conditions and geometry properties (aspect ratio and slenderness ratio) on the shell-solid coupling method. Subsequently the authors' laboratory corrosion data [37] will be implemented in the local 3D model, simulating the stress/strain related material loss over time. The effect of localised geometry change will be assessed within a global model to provide a more realistic prediction of the structural responses.

\section{Acknowledgement}

The authors gratefully acknowledge the funding by the Lloyd's Register Foundation.

\section{References}

[1] J.K. Paik, A.K. Thayamballi, Ultimate strength of ageing ships, Proceedings of the Institution of Mechanical Engineers, Part M: Journal of Engineering for the Maritime Environment, 216 (2002) 57-78.

[2] C. Guedes Soares, P.K. Das, Analysis and design of marine structures, Taylor \& Francis Group, London, UK, 2009.

[3] Y. Wang, J.A. Wharton, R.A. Shenoi, Ultimate strength analysis of aged steel-plated structures exposed to marine corrosion damage: A review, Corrosion Science, 86 (2014) 42-60.

[4] ISSC, Report of Specialist Committee III.1 Ultimate Strength, in: Proceedings of the 18th International Ship and Offshore Structures Congress, Rostock, Germany, 2012, pp. 285-363.

[5] M. Cerit, Numerical investigation on torsional stress concentration factor at the semi elliptical corrosion pit, Corrosion Science, 67 (2013) 225-232.

[6] A. Turnbull, L. Wright, L. Crocker, New insight into the pit-to-crack transition from finite element analysis of the stress and strain distribution around a corrosion pit, Corrosion Science, 52 (2010) 1492-1498.

[7] J. Zhang, X.H. Shi, C. Guedes Soares, Experimental analysis of residual ultimate strength of stiffened panels with pitting corrosion under compression, Engineering Structures, 152 (2017) 70-86. 
[8] Y. Wang, J.A. Wharton, R.A. Shenoi, Influence of localised pit distribution and bench-shape pits on the ultimate compressive strength of steel plating for shipping, CORROSION, 70 (2014) 915927.

[9] Y. Wang, J.A. Wharton, R.A. Shenoi, Ultimate strength assessment of steel stiffened plate structures with grooving corrosion damage, Engineering Structures, 94 (2015) 29-42.

[10] S. Sultana, Y. Wang, A.J. Sobey, J.A. Wharton, R.A. Shenoi, Influence of corrosion on the ultimate compressive strength of steel plates and stiffened panels, Thin-Walled Structures, 96 (2015) 95-104.

[11] S. Saad-Eldeen, Y. Garbatov, C. Guedes Soares, Effect of corrosion severity on the ultimate strength of a steel box girder, Engineering Structures, 49 (2013) 560-571.

[12] Y. Garbatov, S. Saad-Eldeen, C. Guedes Soares, Hull girder ultimate strength assessment based on experimental results and the dimensional theory, Engineering Structures, 100 (2015) 742750.

[13] E. Gucuyen, R.T. Erdem, Corrosion effects on structural behaviour of jacket type offshore structures, Gradevinar, 66 (2014) 981-986.

[14] M. Hairil Mohd, B.J. Lee, Y. Cui, J.K. Paik, Residual strength of corroded subsea pipelines subject to combined internal pressure and bending moment, Ships and Offshore Structures, 10 (2016) 554-564.

[15] D.K. Kim, H.B. Kim, X. Zhang, C. Li, J.K. Paik, Ultimate stregnth performance of tankers associated with industry corrosion addition practices, International Journal of Naval Architeture and Ocean Engineering, 6 (2014) 507-528.

[16] J.K. Paik, S.K. Kim, S.K. Lee, Probabilistic corrosion rate estimation model for longitudinal strength members of bulk carriers, Ocean Engineering, 25 (1998) 837-860.

[17] Y. Bai, Y. Kim, H. Yan, X. Song, H. Jiang, Reassessment of the jacket structure due to uniform corrosion damage, Ships and Offshore Structures, 11 (2016) 105-112.

[18] D. Gao, G. Shi, D. Wang, Residual ultiamte strength of hull structures with crack and corrosion damage, Engineering Failure Analysis, 25 (2012) 316-328.

[19] D.K. Kim, M.S. Liew, S.A.M. Youssef, M. Hairil Mohd, H.B. Kim, J.K. Paik, Time-dependent ultimate strength performance of corroded FPSOs, Arabian Journal for Science and Engineering, 39 (2014) 7673-7690.

[20] X. Jiang, C. Guedes Soares, Ultimate capacity of rectangular plates with partial depth pits under uniaxial loads, Marine Structures, 26 (2012) 27-41.

[21] ISSC, Report of Specialist Committee III.1 Ultimate Strength, in: Proceedings of the 17th International Ship and Offshore Structures Congress, Seoul, Korea, 2009, pp. 375-474.

[22] C. Shi, H. Karagah, M. Dawood, A. Belarbi, Numerical investigation of H-shaped short steel piles with localized severe corrosion, Engineering Structures, 73 (2014) 114-124.

[23] R.M. Pidaparti, A.S. Rao, Analysis of pits induced stresses due to metal corrosion, Corrosion Science, 50 (2008) 1932-1938.

[24] M. Ahmmad, Y. Sumi, Strength and deformability of corroded steel plates under quasi-static tensile load, Journal of Marine Science and Technology, 15 (2010) 1-15.

[25] S. Kainuma, Y. Jeong, J. Ahn, T. Yamagami, S. Tsukamoto, Behavior and stress of orthotropic deck with bulb rib by surface corrosion, Journal of Constructional Steel Research, 113 (2015) 135145.

[26] DNVGL, DNVGL-CG-0127 Finite Element Analysis, in: Class Guidance, 2015.

[27] Lloyd's Register, Fatigue Design Assessment, in: ShipRight Design and Construction, 2009.

[28] J. Harwood, The influence of stress on corrosion, Corrosion, 6 (1950) 249-259.

[29] K. Nobe, S. Tan, Electrical Potential Responses of Silver, Steel and Brass Stressed in Tension In Sodium Chloride Solutions, Corrosion, 18 (1962) 391t-395t.

[30] E.M. Gutman, Mechanochemistry of solid surfaces, World Scientific Publishing Co. Pte. Ltd., Singapore, 1994. 
[31] Y. Wang, W. Zhao, H. Ai, X. Zhou, T. Zhang, Effects of strain on the corrosion behaviour of X80 steel, Corrosion Science, 53 (2011) 2761-2766.

[32] A.R. Despic, R.G. Raicheff, J.O.M. Bockris, Mechanism of the acceleration of the electrodic dissolution of metals during yielding under stress, The Journal of Chemical Physics, 49 (1968) 926938.

[33] L.Y. Xu, Y.F. Cheng, An experimental investigation of corrosion of X100 pipeline steel under uniaxial elastic stress in a near-neutral pH solution, Corrosion Science, 59 (2012) 103-109.

[34] S. Zhang, X. Pang, Y. Wang, K. Gao, Corrosion behavior of steel with different microstructures under various elastic loading conditions, Corrosion Science, 75 (2013) 293-299.

[35] Z.Y. Liu, X.G. Li, Y.F. Cheng, Effect of strain rate on cathodic reaction during stress corrosion cracking of X70 pipeline steel in a near-neutral pH solution, Journal of Materials Engineering and Performance, 20 (2011) 1242-1246.

[36] H.Q. Yang, Q. Zhang, S.S. Tu, Y. Wang, Y.M. Li, Y. Huang, Effects of inhomogeneous elastic stress on corrosion behaviour of Q235 steel in $3.5 \% \mathrm{NaCl}$ solution using a novel multi-channel electrode technique, Corrosion Science, 110 (2016) 1-14.

[37] Y. Wang, J.A. Wharton, J. Downes, R.A. Shenoi, Marine structural integrity subject to mechano-electrochemical induced corrosion, in: NACE CORROSION 2017 Conference and Expo, New Orleans, US, 2017.

[38] L.Y. Xu, Y.F. Cheng, Development of a finite element model for simulation and prediction of mechanoelectrochemical effect of pipeline corrosion, Corrosion Science, 73 (2013) 150-160.

[39] Y. Wang, J.A. Wharton, R.A. Shenoi, Mechano-electrochemical modelling of corroded steel structures, Engineering Structures, 128 (2016) 1-14.

[40] J.K. Paik, D.K. Kim, Advanced method for the development of an empirical model to predict time-dependent corrosion wastage, Corrosion Science, 63 (2012) 51-58.

[41] Y. Garbatov, C. Guedes Soares, Corrosion wastage statistics and maintenance planning of corroded hull structures of bulk carriers, in: C. Guedes Soares, P.K. Das (Eds.) Analysis and Design of Marine Structures, Taylor \& Francis Group, London, UK, 2009.

[42] J. Ahn, S. Kainuma, F. Yasuo, I. Takehiro, Repair method and residual bearing strength evaluation of a locally corroded plate girder at support, Engineering Failure Analysis, 33 (2013) 398418.

[43] N. Khurram, E. Sasaki, U. Akmal, M.U. Saleem, M.N. Amin, A comparative study in utilizing the shell and solid elements formulation for local corrosion simulation at bearing stiffener, Arabian Journal for Science and Engineering, (2016).

[44] G. Crammond, S.W. Boyd, J.M. Dulieu-Barton, Evaluating the localised through-thickness load transfer and damage initiation in a composite joint using digital image correlation, Composite: Part A, 61 (2014) 224-234.

[45] J. Kovac, T.J. Marrow, E. Govekar, A. Legat, Detection and characterisation of intergranular stress-corrosion cracking on austenitic stainless steel, Materials and Corrosion, 63 (2012) 664-673.

[46] H. Ghadbeigi, C. Pinna, S. Celotto, Quantitative strain analysis of the large deformation at the scale of microstructure: comparison between digital image correlation and microgrid techniques, Experimental Mechanics, 52 (2012) 1483-1492.

[47] V. Savic, L.G. Hector, J.R. Fekete, Digital image correlatino study of plastic deformation and fracture in fully martensitic steels, Experimental Mechanics, 50 (2010) 99-110.

[48] H. Karagah, C. Shi, M. Dawood, A. Belarbi, Experimental investigationofshortsteelcolumnswith localised corrosion, Thin-Walled Structures, 87 (2015) 191199.

[49] M.A. Sutton, J. Orteu, H.W. Schreier, Image correlation for shape, motion and deformation measurements, Springer Science+Business Media, LLC, New York, 2009.

[50] LaVision, DaVis 8.0 Software product manual, (2012).

[51] T. Hutt, P. Cawley, Feasibility of digital image correlation for detection of cracks at fastener holes, NDT\&E International, 42 (2009) 141-149. 
[52] D.A. Crump, J.M. Dulieu-Barton, J. Savage, Design and commission of an experimental test rig to apply a full-scale pressure load on composite sandwich panels representative of an aircraft secondary structure, Measurement Science and Technology, 21 (2010).

[53] Abaqus, Abaqus 6.14 Documentation, in, Dassault Systèmes, 2014.

[54] C.S. Smith, P.C. Davidson, J.C. Chapman, P.J. Dowling, Strength and stiffness of ships' plating under in-plane compression and tension, RINA, Trans., 130 (1988) 277-296.

[55] M.A. Crisfield, A fast incremental/iteration solution procedure that handles 'snap-through', Computers and Structures, 13 (1981) 55-62.

[56] ISSC, Report of Specialist Committee III.1 Ultimate Strength, in: Proceedings of the 19th International Ship and Offshore Structures Congress, Cascais, Portugal, 2015, pp. 280-349. 
- A transition study for developing interactive corrosion-structure models

- Explore methods of linking shell to solid elements in thin-walled structural FEA

- Method allows the use of mechanical-electrochemical test data on large structures

- Use 3D digital image correlation in elastic-plastic buckling experiments

- Full-field test data agree well with numerical results in elastic/plastic regimes 


\title{
Assessing the performances of elastic-plastic buckling and shell-solid combination in finite element analysis on plated structures with and without idealised corrosion defects
}

\author{
Y. Wang ${ }^{1,2}$, J. Downes ${ }^{1,2}$, J.A. Wharton ${ }^{3}$ and R.A. Shenoi ${ }^{1,2}$ \\ 1. Fluid Structure Interactions Group, University of Southampton, Southampton, UK \\ 2. Southampton Marine and Maritime Institute, University of Southampton, Southampton, UK \\ 3. National Centre of Advanced Tribology at Southampton, University of Southampton, Southampton, \\ UK
}

\begin{abstract}
Ships and offshore structures operate in harsh and corrosive environments and they are subject to high hydrodynamic and inertial loads. Thus it is important to accurately predict the mechanical response of thin-walled marine structures subject to corrosion damage in loaded conditions. This paper present a transition study to investigate in depth the usage of shell and solid elements in nonlinear finite element structural analysis with localised corrosion features. An experimental, stereo full field imaging technique, 3D digital image correlation is used to verify both the shell and solid modelling results. The solid-to-shell coupling techniques were subsequently assessed based on a deck plate model. Models containing a localised section using either the second-order hexahedral element C3D20 or tetrahedral element C3D10I show a similar performance that is compatible with the model using only shell element. The proposed coupling method works well for localised electrochemical or mechanical-electrochemical analysis with subsequent geometrical updates.
\end{abstract}

Keywords: finite element method; digital image correlation; buckling; model coupling; corrosion.

\section{Nomenclature}

a Length of the deck plate model / $\mathrm{mm}$

$b \quad$ Width of the deck plate model / $\mathrm{mm}$

C Correlation function

$d_{\mathrm{p}} \quad$ Position tolerance for the surface-based approach / $\mathrm{mm}$

$\boldsymbol{e}_{i} \quad$ Current configuration base vector (regardless of rotation constraint at the slave node)

E Young's modulus / GPa

$F \quad$ Grey value matrix of reference image

$\boldsymbol{F}^{\text {Shell }}$ Force distribution at the reference shell node

$F_{i}^{\text {Solid }} \quad$ Force distribution at the coupling solid node $i$

$G \quad$ Grey value matrix of deformed image

I Second-order identity tensor

$k \quad$ Smallest integral satisfying $a / b \leq \sqrt{k(k+1)}$

$m \quad$ Pixel location in the reference image

$\boldsymbol{M}^{\text {Shell }}$ Moment at the reference shell node

$n \quad$ Pixel location in the reference image

$\boldsymbol{n} \quad$ Normal direction of the deformed solid configuration

$N \quad$ Subset size

$\boldsymbol{N} \quad$ Normal direction of the reference solid configuration

$\boldsymbol{r}_{\mathrm{i}} \quad$ Influence distance at the coupling solid node $i$ for the surface-based approach / $\mathrm{mm}$ 
$\boldsymbol{R}\left(\boldsymbol{\phi}^{\mathrm{m}}\right)$ Rotation matrix associated with the master node rotation $\boldsymbol{\phi}^{\mathrm{m}}$

$\boldsymbol{S} \quad$ Skew symmetric matrix form of the rotation vector $\boldsymbol{\phi}$

$t_{\mathrm{p}} \quad$ Thickness of the deck plate model / $\mathrm{mm}$

$\boldsymbol{T} \quad$ Coupling node arrangement inertia tensor

$u$ Displacement of the subset centre from the reference image to the deformed image $/ \mathrm{mm}$

$\boldsymbol{u}^{\text {Shell }}$ Displacement of the shell node

$\boldsymbol{u}_{i}^{\text {Solid }}$ Displacement of the solid node $i$

$v \quad$ Displacement of the subset centre from the reference image to the deformed image / $\mathrm{mm}$

$w_{i} \quad$ Weighing factor at solid node $i$

$\bar{w}_{\mathrm{i}} \quad$ Nominalised weight factor

$w_{\mathrm{p}} \quad$ Deck plate initial deflection

$x^{\mathrm{m}} \quad$ Deformed configuration position of master node

$\overline{\boldsymbol{x}}^{\mathrm{s}} \quad$ Fully constrained slave node position

$\boldsymbol{x}^{\mathrm{S}} \quad$ Partially constrained slave node position

$\boldsymbol{x}^{\text {Shell }}$ Positions of the reference shell node

$\boldsymbol{x}_{\mathrm{i}}^{\text {Solid }}$ Positions of the coupling solid node $i$

$\boldsymbol{X}^{S} \quad$ Reference configuration positions of the slave node

$\boldsymbol{X}^{\mathrm{m}} \quad$ Reference configuration positions of the master node

$y_{i} \quad$ Translation degree of freedom $i$ at the additional node $/ \mathrm{mm}$

$\beta \quad$ Slenderness ratio

$v \quad$ Poisson ratio

$\sigma_{\mathrm{y}} \quad$ Yield stress of the material / $\mathrm{MPa}$

$\phi \quad$ Rotation vector

$\boldsymbol{\phi}^{\mathrm{m}} \quad$ Master node rotation

\section{Introduction}

Corrosion damage accumulation in association with thin-walled structural resilience in marine environments has been an area of study over the last few decades [1-3]. The accuracy of the structural analysis can directly affect reliability prediction and maintenance or repair strategies [4]. Depending on the structural location, material properties, and the service environment, corrosion damage either can spread over the entire plating, become localised in regions that are associated with a failed protection system (i.e., polymeric coating defects or cathodic protection problems) or be linked to complex geometrical surfaces including weld imperfections. Figure 1 shows an example of such an imperfection along a butt weld. Rough surfaces due to corrosion and rust can be potential stress concentration sites and thus a threat to structural reliability [5-7]. To assess these corrosion effects, numerous studies have been undertaken on plated or tubular marine structures containing representative corrosion features [3, 8-14]. Among the limited analysis approaches, the finite element method with fully nonlinear material and geometric properties is commonly used to predict ultimate strength capacity primarily for small scale or individual structural members with corrosion damage. Many finite element analysis (FEA) models use a two-dimensional (2D) 4-node shell element to simulate structures which require modelling of sections of plating, box girders and hull girders. In these scenarios, the corrosion damage is normally idealised as a uniform thickness reduction especially for hull girder and platform simulations [15-19]. Smaller models with local 
thickness variations have also been studied where different section properties need to be assigned to shell elements $[3,10,20]$. Verifications by both laboratory and practical experience have shown that under appropriate boundary conditions and hourglass control, shell elements are capable of accurately predicting the ultimate strength of intact plated structures at low computational cost and with less modelling effort $[4,8,21,22]$. In comparison, models built by either three-dimensional (3D) solid elements show an enhanced ability to simulate more realistic corrosion topographies [6, 23]. Surface mapping tools can be used to transfer actual corroded surface features directly to a $3 \mathrm{D}$ model [9, 23-25]. Therefore, detailed stress and strain distributions can be obtained for the surface. However, shear and volume locking may occur in such models that prevent thin-walled structure behaviour. The high computational cost also indicates that it is almost impossible to use solid models for rapid strength prediction of ship hulls or offshore platforms practically [26, 27].

Alternatively, for marine structures with 15 to 20 years of operational service, the accumulation and evolution of corrosion damage will result in progressive changes in structural geometry and hence influence strength capacity. There is sufficient evidence to indicate a clear interplay between corrosion and stress / strain distributions for mechanically loaded surfaces [28-30]. Under these situations, corrosion may be significantly accelerated resulting in a so-called mechanically-assisted corrosion [30-32]. Theoretical and laboratory investigations have aimed to understand this mechanical -electrochemical corrosion behaviour [33-36]. Recently, the authors have also conducted a series of in situ tests and obtained corrosion data for shipping grade carbon steels under tensile stress [37] which showed a clear dependence of the corrosion kinetics on tensile stresses. However, such corrosion data can only be utilised effectively on actual marine structures if the stress and strain predictions are reliable, especially for surfaces with complex geometrical features. To date, only a few small-scale numerical studies are available in the open literature simulating long-term corrosion degradation from the electrochemical or mechanical-electrochemical standpoint, with no further corresponding structural performance assessment [37-39]. Nearly all large-scale structural analysis that considers the influence of corrosion with time use statistical models and field / survey data [40,41]. Although these databases may contain the holistic effects for a range of corrosion factors, the lack of an up-to-date database and insufficient data quantity can result in unrealistic damage prediction. Moreover, the effect of localised corrosion damage on the overall structural performance is not sufficiently understood at the appropriate spatial and temporal scales necessary.

Therefore, there is a drive to develop an interactive corrosion-structure modelling strategy where electrochemical or mechanical-electrochemical theories and laboratory data can be implemented, i.e., the model is capable of accurately predicting the detailed stress / strain distributions on the structural surface with corrosion. The developed model should also be computationally economical for large-scale analysis so as to enable implementation into standard structural modelling practices. This paper presents a transition study, in addition to the authors' corrosion experimental work [37], towards the corrosion-structure model development for aging ships and offshore platforms.

Firstly, to guarantee the reliability of the FEA models, a novel stereo full field imaging experimental technique, namely digital image correlation (DIC), is used to validate the numerical method. Due to the geometric complexity of the corrosion damage, identifying the early stress/strain concentrations around the defect are of great importance when assessing the structural resilience. However, to date, most of this information is obtained by numerical studies. For elastic-plastic buckling scenarios, the validation of such numerical models are often carried out by simply comparing the loadshortening curves to experiments. There is little full-field experimental work available in the 
literature validating the surface stress and/or strain on an uneven surface. The DIC study in this paper fills the gap by providing physical evidence of strain and displacement distributions on the specimen surface with various local damage. Secondly, localised corrosion is increasingly more of a concern for aging ships and offshore structures, therefore this work proposes to combine a detailed local corrosion model (preferably using solid elements) with a global shell model. Although there are several existing models with a mixture of shell and solid elements [25, 42, 43], the connection at the interface and the actual modelling technique were not explicitly stated. In the current study, the shell-to-solid constraining techniques are thoroughly assessed based on a simply supported deck plate model.

\section{Methodology}

\section{Digital Image Correlation (DIC)}

DIC enables a full field measurement of deformation and displacement and has been successfully utilised in monitoring crack propagations and large plastic deformation of various materials [44-48]. The concept is to evaluate the object deformation by tracking deformation of a random pattern in an image. Each pixel within an image has a grey value. DIC applies a stochastic speckle pattern to provide unique information of a small aperture (subset or interrogation cell) for pattern matching on the specimen surface. The motion estimation method is based on minimising the squared difference in grey values, namely a summation of squares deviation. The correlation function is expressed as follows [49]:

$$
C(m, n, u, v)=\sum_{i, j=-N / 2}^{N / 2}[G(m+u+i, n+v+j)-F(m+i, n+j)]^{2}
$$

where $m$ and $n$ denote the pixel location in the reference image; $u$ and $v$ represent the displacements of the subset centre from the reference (undeformed) image to the deformed image; $N$ is the size of the subset; $G$ and $F$ are the grey value matrices of deformed and reference images, respectively. More detailed DIC information can be found in Ref [49].

For the current study LaVision DaVis 8.1.0 correlation software was adopted employing the least square method to iteratively approximate the deformation [50]. The iteration starts from the selected seeding point(s) and the analysed region grows with the existing information utilised as a predictor for a possible match. After identifying all subsets in the deformed image, the displacement data can be converted to Lagrangian strain tensor or engineering strain for the area of interest. Once the surface deformations are obtained, DaVis uses a central difference scheme to compute the strain values [50]. A single charge-coupled device (CCD) camera cannot distinguish uniform strain from uniform out-of-plane displacement [51]. By using a two-camera stereo set-up (3D DIC), the calibration process helps build a 'working volume' and informs the positions of the two cameras relative to each other [52] to calculate the out-of-plane deformation.

The present study used a servo-hydraulic test machine Instron 8032 to apply quasi-static uniaxial compressive loading by displacement control $\left(1 \mathrm{~mm} \mathrm{~min}^{-1}\right)$. The specimen weight and the test jig were balanced out prior to external loading. The experimental set-up is shown in Figure 2. Two 5 megapixel 12-bit monochromatic LaVision E-lite CCD cameras were used with two Sigma 105 lenses 
(Figure $2 \mathrm{~b}$ ). The cameras were positioned with viewing directions $30^{\circ}$ relative to each other in front of the specimen. A floodlight was used to enhance the illumination. The deformation was recorded at a frequency of $1 \mathrm{~Hz}$, including the load and displacement provided by the Instron machine. Steel jigs were designed specifically for such thin wide column compressive tests, as shown in Figure 2a, where the two lubricated pillars were press fit at the bottom and free slide at the top, in order to achieve a uniform in-plane compressive stress. Specimen surface finish consisted of a matt black paint with white speckles. The average speckle size was five pixels across and the spatial resolution was 24.4 pixels $\mathrm{mm}^{-1}$.

Four DIC specimens were fabricated from Grade 070M20 steel with dimensions: $110 \mathrm{~mm} \times 90 \mathrm{~mm}$ $\times 3 \mathrm{~mm}$ (actual test area: $90 \mathrm{~mm} \times 90 \mathrm{~mm}$ ); and four one-side idealised corrosion patterns shown in Figure 3. Before commencing the buckling tests, the initial deflections of all specimens were measured using an Aberlink 3D Faro Arm (single point $0.01 \mathrm{~mm}$ ) at discrete locations across the specimen surface. The measured initial deflections for the four corrosion patterns are shown in Figure 4. Both top and bottom edges of the specimen were clamped to the specifically designed jigs. The damage area was $15 \%$ and depth was $1.25 \mathrm{~mm}$ for all DIC specimens. A compressive load was applied quasi-statically at $1 \mathrm{~mm} \mathrm{~min}^{-1}$ with the entire loading procedure monitored by a stereo camera system at $1 \mathrm{~Hz}$ in order to capture the ultimate strength point. For data processing, the subset size was set to be $61 \times 61$ pixels while the step size (grid spacing) was 19 pixels, leading to a $31 \%$ overlap. The correlation mode was set to be the sum of differential of the preceding images, which is suitable for large deformation over time. Since the test jig experienced elastic deformations during the loading process, strain values instead of displacement along the load direction were examined.

\section{Coupling shell and solid model techniques}

The commercial FEA package Abaqus is a popular tool in both research and industry for performing structural analysis due to its robust nonlinear solver and versatility via command lines and Python scripting. However, little information or study is available in the open literature showing the software performance when combining shell and solid elements. In a combined shell-solid model, the transition from a shell edge to a multi-layered solid cross-section can be achieved by using either constraint formulations or a sub-modelling technique. Particularly, three types of constraint methods are available: (i) multi-point constraints (MPC), (ii) kinematic coupling and (iii) surfacebased shell-to-solid coupling constraint. The MPC in combination with the SLIDER constraint (SS LINEAR, SS BILINEAR, SSF BILINEAR) enforces the same displacement and compatible rotation at the shell and solid interface while maintaining straight lines through the solid thickness. Weighting functions were used for the solid nodes through thickness [53]:

$$
\boldsymbol{u}^{\text {Shell }}=\sum_{i=1}^{n} w_{i} \boldsymbol{u}_{i}^{\text {Solid }}
$$

where $\boldsymbol{u}^{\text {Shell }}$ is the displacement of the shell node; $\boldsymbol{u}_{i}^{\text {Solid }}$ is the displacement of the solid node; $w_{i}$ is the weighing factor based on the MPC type and solid nodal locations. The shell-to-solid MPC needs to be defined individually at each node along the shell facets. Moreover, the lines of throughthickness solid nodes need to be preferably aligned with shell nodes, which limits the flexibility of meshing the solid model. 
Kinematic coupling constraints the degrees of freedom (DOFs) of a set of slave nodes to a master node by creating an additional node internally for each slave node. For a fully constrained slave node, the displacement and rotations are calculated as follows [53]:

$$
\boldsymbol{R}\left(\boldsymbol{\phi}^{\mathrm{m}}\right) \cdot\left(\boldsymbol{X}^{\mathrm{s}}-\boldsymbol{X}^{\mathrm{m}}\right)=\overline{\boldsymbol{x}}^{\mathrm{s}}-\boldsymbol{x}^{\mathrm{m}}
$$

where $\boldsymbol{X}^{\mathrm{s}}$ and $\boldsymbol{X}^{\mathrm{m}}$ are the reference configuration positions of the slave node and master node respectively; $\overline{\boldsymbol{x}}^{\mathrm{s}}$ is the fully constrained slave node position in the current configuration; $\boldsymbol{x}^{\mathrm{m}}$ is the current configuration position of the master node; and $\boldsymbol{R}\left(\boldsymbol{\phi}^{\mathrm{m}}\right)$ is the rotation matrix associated with the master node rotation $\phi^{\mathrm{m}}$. Partially constrained slave node position can be calculated by adding a DOF term to $\overline{\boldsymbol{x}}^{\mathrm{s}}$.

However, this method does not enforce the straightness of the through-thickness lines, and hence does not comply with either Kirchhoff or Mindlin shell theories. It is also difficult to define the actual control area on solid cross-sections.

In comparison to the two node-based constrain methods, the surface-based approach minimises numerical noise at the shell-solid interface where mismatched meshes exist. The internally distributed constraints couple the DOFs of each shell surface (edge facets) to the average DOFs of the solid surface (node- or element-based). A position tolerance $d_{\mathrm{p}}$ is used to determine the shell nodes that act as reference nodes, while within an influence distance $\boldsymbol{r}_{\mathrm{i}}$ normal from the shell edge, the node or element facet on the solid surface will be included in the coupling constraint. The force distributions satisfies:

$$
\begin{gathered}
\sum \boldsymbol{F}_{\mathrm{i}}^{\text {Solid }}=\boldsymbol{F}^{\text {Shell }} \\
\sum \boldsymbol{x}_{\mathrm{i}}^{\text {Solid }} \times \boldsymbol{F}_{i}^{\text {Solid }}=\boldsymbol{M}^{\text {Shell }}+\boldsymbol{x}^{\text {Shell }} \times \boldsymbol{F}^{\text {Shell }}
\end{gathered}
$$

where $\boldsymbol{x}_{\mathrm{i}}^{\text {Solid }}$ and $\boldsymbol{x}^{\text {Shell }}$ are positions of the coupling nodes and reference node respectively; load $\boldsymbol{F}^{\text {Shell }}$ and moment $\boldsymbol{M}^{\text {Shell }}$ are at the reference node; and $\boldsymbol{F}_{i}^{\text {Solid }}$ is the force distribution at coupling node $i$. Similar to the MPC constraint, a distributing weight factor $w_{i}$ is assigned at each solid node. The linear motion of the reference node is compatible with the averaged coupling group motion, which results in a linearised constraint between the reference node and coupling nodes. More detailed formulations can be found in Ref. [53].

The sub-modelling technique is another option to link a global shell model and a local solid submodel. Any time-dependent results at the interface are interpolated from the global model to the submodel [53]. However, it is only suitable when the submodel performance has a negligible effect on the global solution. To reveal the influence of corrosion damage on the overall structural response, as well as to obtain more detailed stress / strain results at the damaged region, the surface-based shell to solid coupling approach was chosen in this study, for its transition of weighed forces / moments and relatively low computational effort. Both element- and node-based solid surfaces were examined. The position tolerance $d_{\mathrm{p}}$ when using an element-based solid surface was $5 \%$ of the length of the coupling facet on the shell edge [53]. When using a node-based solid surface, $d_{\mathrm{p}}$ is based on the average distance between nodes on the solid surface. The value of the influence radius $\boldsymbol{r}_{\mathrm{i}}$ for an edge facet was half the thickness of the underlying shell element. 


\section{DIC and shell-solid models}

In addition to the shell-solid models, the DIC specimens were also analysed numerically. For the DIC model, the geometry was the same as used in the experiments. Both the top and bottom edges were clamped with a uniaxial compressive displacement applied at the bottom edge. To facilitate the modelling process for comparison, surface fittings were performed using the Faro Arm mapping data to obtain a polynomial function ( $R^{2}$ values are above 0.95 ), based on which the nodal location was updated to generate a realistic initial deflection. After the application of initial deflection using polynomial functions, both the loaded edges were straightened and the deflections were updated accordingly. The shell-solid model is based on a Panamax class tanker deck plate with dimensions of $3900 \mathrm{~mm} \times 830 \mathrm{~mm} \times 8 \mathrm{~mm}$ [15]. The boundary condition was simply supported along the four edges for the shell-solid model, as illustrated in Figure 5. A Fourier form of initial deflection $w_{\mathrm{p}}$ (Eq. 6) was applied to the plate, which is suggested by Smith et al. [54].

$$
w_{\mathrm{p}}=0.1 \beta^{2} t_{\mathrm{p}} \sin \left(\frac{k \pi x}{a}\right) \sin \left(\frac{\pi y}{b}\right)
$$

where $\beta=b / t_{\mathrm{p}} \sqrt{\sigma_{\mathrm{y}} / E}$ is the slenderness ratio; $a$ is the length of the plate; $b$ is the width of the plate; $t_{\mathrm{p}}$ is the thickness of the plate; $\sigma_{\mathrm{y}}$ is the yield stress of the material; $k$ is the smallest integral satisfying $a / b \leq \sqrt{k(k+1)}$, which is equal to 5 for the current model geometry. The stress-strain relationship of the DIC specimens are shown in Figure 6 from standard tensile tests. It can be seen that the tested steel shows little strain hardening behaviour. Therefore, for simplicity, an elasticperfectly-plastic constitutive model was assigned for the DIC columns. Similar constitutive model was also used for the deck plates from a conservative point of view. All material properties are listed in Table 1.

A nonlinear buckling analysis assesses the stability characteristics of a structure. To obtain the ultimate strength point or critical buckling load, there are main two quasi-static analysis methods, namely Newton-Raphson (NR) algorithm and Riks algorithm (arc length method). The time dependent NR method has a quadratic convergence rate and applies adaptive bisections when convergence difficulty occurs. However, when the post-buckling path is unstable with much increased deformation, divergence is inevitable no matter how small the substep size is. In comparison, the Riks method uses an extra constraint and allows a convergence at lower applied load. The load during one-step is always proportional to the current load magnitude. Due to the ability to handle both stable and unstable post-buckling behaviour, which is difficult to predict prior to an analysis especially when corrosion damage presents, all models were solved using the Riks algorithm [55]. Linear shell element with hourglass control is a common choice for thin-walled marine structural analysis due to its flexibility and low computational cost [4, 21,56]. Therefore, the quadrilateral shell element S4R with reduced integration and enhanced hourglass control [53] was primarily chosen here to construct the DIC and the global shell models. At the damaged area with reduced thickness, the shell section was defined separately and the reference plane was offset. Five integration points were used for each shell cross-section. Based on mesh convergence studies (example shown in Figure 7a), the element size ranged between $0.7 \mathrm{~mm}$ and $3.0 \mathrm{~mm}$ for the DIC model. The mesh patterns used for DIC models are shown in Figure 3. For the deck plate model, the typical element size was $40 \mathrm{~mm}$, which showed a decreased stiffness in the post-buckling region in Figure $7 \mathrm{~b}$. It is interesting to note that there is a slight change in the ultimate stress at the finest mesh $(10 \mathrm{~mm})$. This is considered to be due to that the characteristic length of the shell element used is almost equal to the thickness of the deck plate $(8 \mathrm{~mm})$. Although there is no theoretical limit 
on the element size relative to thickness, for S4R element, the thick shell theory is used when the shell thickness increases. For elastic-plastic buckling analysis, when all shell elements are no longer "thin-walled" (characteristic element length is much larger than thickness), the global behaviour of the plate is changed, which produces a less physically accurate result compared to the four data points at a mesh size of 20 to $80 \mathrm{~mm}$.

For the local 3D section shown in Figure 5 aiming for a greater geometrical detail, hexahedral and tetrahedral elements were considered. The dimension of the 3D model was $0.3 \mathrm{~m} \times 0.3 \mathrm{~m} \times 0.008$ $\mathrm{m}$. In general, a hexahedral element has a better convergence rate than a tetrahedral element. However, the latter is less sensitive to the initial element shape, and hence could be more suitable for simulating a corroded topography [53]. Therefore, the studied elements included first-order hexahedral C3D8R with reduced integration to avoid volume / shear locking, C3D8R with enhanced hourglass formulation, second-order hexahedral C3D20 and C3D20R with full and reduced integration respectively and second-order tetrahedral elements C3D10I and C3D10. Specifically, the C3D10I has ten integration points of locations coincide with the nodes and one in the centre of the element, which improves the surface stress visualisation. Shear locking is also avoided for this element type. Typical solid element size is similar to the shell model, with four layers through thickness. Three locations of the local solid model were examined, as illustrated in Figure 5.

\section{Results and discussion}

\section{DIC experiments and models}

Figure 8 shows the average stress-strain relationships for all specimens from the DIC and FEA. It can be seen that the shell models give a good prediction up to the ultimate strength. The FEA ultimate strengths are higher than the DIC results, ranging from 3.9\% (corrosion at the corner) to $11.8 \%$ (corrosion on the unloaded edge). In the post-buckling region, FEA appears to underestimate the stress compared to the experimental results, as seen in Figure 8. The specimen manufacture is considered as the main source of discrepancy between DIC and FEA. Firstly, initial deflections were induced by machine marks and measured on a coarse grid on the specimens ( $10 \times 10$ data points) due to the limitation of the Faro Arm resolution. Although the polynomial functions show a good fitting $\left(R^{2}>0.95\right)$, some local variation around the defect were not included. Secondly, the clamped boundary condition was achieved on a $90 \mathrm{~mm} \times 10 \mathrm{~mm}$ region using a steel strip and four $\mathrm{M} 6$ bolts on each side (Figure 9). Since the model did not include the rigs that clamped the top and bottom edges of the specimen, the induced pre-loading to the specimen was not taken into account, and therefore led to a higher ultimate strength and lower unloading path [9, 21]. Detailed investigation of the pre-stress effect was discussed in the authors' previous work [9]. Thirdly, the milling of the defects on the specimen surfaces may introduce a small amount of initial stresses, which could contribute to the discrepancies between experimental and FEA results.

When examining deformation and strain distributions at the ultimate strength point, the FEA show good agreement with DIC when capturing various failure modes depending on the location of the corrosion damage. Figure 10 shows examples of the FEA and DIC contour plots for a random corrosion pitting condition. By keeping the same average stress in the post-buckling region, again similar out-of-plane deformation and in-plane strain distributions were obtained from DIC and FEA. Figure 11 is an example of the specimen with random pitting damage when the reaction force is 70 
$\mathrm{kN}(260 \mathrm{MPa})$ in the post-buckling region, as indicated in Figure 8c. Visually, the out-of-plane deformation results (Figures 11a and 11b) are consistent in terms of distribution and magnitude. The in-plane strain in the loading direction also show a similar distribution from both techniques. However, discrepancies (Figures $11 \mathrm{c}$ and $11 \mathrm{~d}$ ) around the pitting edges increase compared to the ultimate strength stage (Figure 10c and 10d). Although seeding points were carefully selected around the defect edges (thickness discontinuity), there are still some regions that the DIC failed to correlate, for example the red squares in Figures 10a and 11a. The smaller subset size $(41 \times 41$ pixels) was tested resulting in limited improvement in the correlation area. In terms of strain maps, DIC achieves a high strain resolution (in the order of $10^{-3}$ ). However, noise can be seen since strain values were calculated based on the displacement results for DIC. Moreover, strains that are unrealistically high in magnitude were obtained around the defect. This is due to the discontinuous deformation inside and outside of the defect. In DIC, the deformation discontinuity around the defect edge is averaged for calculating strains, and hence could result in unrealistic strain values. Overall, the nonlinear FEA models using shell elements have been successfully verified using the DIC method. However, the buckling mode of the specimens is largely dependent on the initial state (geometric imperfection and initial stress) which may be difficult to accurately simulate.

The tetrahedral solid element C3D10I was also used to construct the DIC models. Figure 12 shows an example of the comparison results for the random pitting specimen. It is evident that the average compressive stress-strain curves obtained from the solid model is almost identical to the shell result. Similar von Mises stress distributions were obtained at ultimate strength for both models (Figure 12b and 12c). Nevertheless, examining the local stress values in detail, a non-real stress discontinuity can be found around the defect edges when connecting two shell facets with different section features. Moreover, depending on the method deployed, a range of results could be obtained for the same stress component on the same element, especially at the shared mid-plane nodes. Although the stress discontinuity in the pit using shell element has little influence on the overall structural behaviour (ultimate strength and load-shortening curves), corrosion experiments [28-30, 33-36] have shown that these areas are key for reducing rust layer integrity and potential corrosion acceleration, which may subsequently lead to cracking and change the corrosion appearance. Inconsistency of the shell normals will cause difficulty in obtaining the top and bottom surface stresses and strains. In comparison, the solid model shows a more realistic stress distribution at geometrical discontinuities, which again proves that although shell model is able to predict the overall ultimate strength capacity, local hot spot stresses are more readily accessible from solid elements. Therefore, to continuously update the structural thickness and the surface stress / strain, solid elements are considered to be a better option in the authors' future work.

\section{$\underline{\text { Shell-solid deck plate models }}$}

The deck plate model of the dimensions given in Table 1 was first constructed using only either shell or solid elements. To achieve the simply supported boundary condition, displacement constraints were applied at the mid-thickness on the solid models. Figure 13 shows the average compressive stress-strain curves from one shell element (S4R with and without enhanced hourglass control) and three solid elements (C3D8R and C3D8R with enhanced hourglass control, C3D20 with and without reduced integration and C3D10 with and without improved stress visualisation). In particular, the C3D8R model deviates from the rest of the result from the onset of loading. Due to the reduced integration with only one integration point, the locking problem is avoid in C3D8R. However, without the enhanced hourglass control, the element is overly stiff compared to the shell model. The von Mises stress distribution also shows stress discontinuity on both sides of the plate (Figure 
13). Conversely, the 20-node solid element C3D20R with reduced integration estimates a lower stress level both in the elastic and plastic buckling regions. An obvious hourglass mode can be observed at the constrained boundaries (Figure 13). The rest of the elements all present similar stress-strain curves and ultimate strength values, apart from the C3D10 model where the loss of stiffness occurs at a larger compressive deformation / strain. Therefore, based on the experimental results from the previous section, elements C3D8R with enhanced hourglass control, C3D20, C3D10 and C3D10I are potentially valid for thin-walled nonlinear buckling analysis.

Figure 14 compares the shell-solid coupling results between node-based and element-based solid interfaces for Location 1 (Figure 5). All element-based stress-strain curves are close to the one obtained from the shell model, with approximately $1 \%$ lower ultimate strength value. Post-buckling performance from C3D8R shell-solid element-based model shows an improved estimate than the node-based approach. There was little difference between the element- and node-based C3D20 models up to the post-buckling region (large deformation and rotation), due to the higher density of nodes compare to the linear elements. However, the node-based C3D10 and C3D10I models significantly underestimate the ultimate strength and strain, indicating that the second-order tetrahedral elements are more sensitive to the coupling node selection, especially under large deformation. For models with element-based solid surface, the failure modes are similar to the shell model.

Figure 15 shows the out-of-plane displacement and von Mises stress at mid-width in y-direction at the model's ultimate strength. In comparison with the shell model, the C3D20 and C3D10I models show similar displacements, whereas C3D10 and C3D8R over- and underestimate the maximum deformation, respectively (Figure 15a). For the shell-solid coupling models, all solid elements give close estimate to the shell model results. In Figure 15b, the von Mises stresses were obtained by averaging extrapolated corresponding element results when the difference between two elements is within 75\%, which leads to nosier data especially for C3D10 and C3D10I. All solid coupling models predict a similar stress distribution as the shell result. However, the model built only using C3D10 over predicts stress. The local results also corresponds with the global stress-strain relationships presented in Figures 13 and 14. It is therefore considered that the tetrahedral element performance is more affected by the simply supported boundary condition. In the shell-solid coupling scenario, the constraints along the shell edge facets lead to a more stable solid element behaviour. Figure 16 are the average stress-strain curves derived for Locations 2 and 3 (Figure 5) using element-based

solid surfaces. Depending on the assigned initial deflection, different locations would results in the solid section with different buckling shape and magnitude (Figure 17). However, the element-based shell-solid coupling method is able to provide a good estimate compared to the shell model regardless of the solid model location.

\section{Conclusion}

This paper presents a comparison between full field experimental measurement and FEA modelling regarding the elastic-plastic buckling scenario. It also explores the performances of a range of shell and solid elements and the feasibility of shell-solid coupling models in an FEA thin-walled structural analysis for both intact and damaged surfaces. Main findings are as follows: 
- The 3D DIC experimental technique on partially damaged steel specimens shows a great potential in assessing quasi-static buckling failure stress/strain and providing a full field failure mode measurements;

- A good agreement has been achieved between the DIC and FEA results in capturing the nonlinear buckling process and the local displacement/strain discontinuity around the artificial pitting damage;

- For both global and local models, the second-order hexahedral element and tetrahedral element result in consistent behaviour that is compatible with a shell model in terms of failure mode and stress distribution;

- The second-order tetrahedral elements are more sensitive to the coupling node selection, especially under large deformation;

- The shell-solid coupling method should be capable of transferring both displacement and force/moment at the shell-solid interface to provide good estimate compare to the shell model regardless of the solid model location.

Based on the current interactive corrosion-structure modelling strategy and validation, this enables reliable stress and strain predictions especially for structures with geometric complexities, which would be beneficial for effective implementation of experimental corrosion data for localised electrochemical or mechanical-electrochemical analysis. Future work will be conducted to investigate the effects of other boundary conditions and geometry properties (aspect ratio and slenderness ratio) on the shell-solid coupling method. Subsequently the authors' laboratory corrosion data [37] will be implemented in the local 3D model, simulating the stress/strain related material loss over time. The effect of localised geometry change will be assessed within a global model to provide a more realistic prediction of the structural responses.

\section{Acknowledgement}

The authors gratefully acknowledge the funding by the Lloyd's Register Foundation.

\section{References}

[1] J.K. Paik, A.K. Thayamballi, Ultimate strength of ageing ships, Proceedings of the Institution of Mechanical Engineers, Part M: Journal of Engineering for the Maritime Environment, 216 (2002) 57-78.

[2] C. Guedes Soares, P.K. Das, Analysis and design of marine structures, Taylor \& Francis Group, London, UK, 2009.

[3] Y. Wang, J.A. Wharton, R.A. Shenoi, Ultimate strength analysis of aged steel-plated structures exposed to marine corrosion damage: A review, Corrosion Science, 86 (2014) 42-60.

[4] ISSC, Report of Specialist Committee III.1 Ultimate Strength, in: Proceedings of the 18th International Ship and Offshore Structures Congress, Rostock, Germany, 2012, pp. 285-363.

[5] M. Cerit, Numerical investigation on torsional stress concentration factor at the semi elliptical corrosion pit, Corrosion Science, 67 (2013) 225-232.

[6] A. Turnbull, L. Wright, L. Crocker, New insight into the pit-to-crack transition from finite element analysis of the stress and strain distribution around a corrosion pit, Corrosion Science, 52 (2010) 1492-1498.

[7] J. Zhang, X.H. Shi, C. Guedes Soares, Experimental analysis of residual ultimate strength of stiffened panels with pitting corrosion under compression, Engineering Structures, 152 (2017) 70-86. 
[8] Y. Wang, J.A. Wharton, R.A. Shenoi, Influence of localised pit distribution and bench-shape pits on the ultimate compressive strength of steel plating for shipping, CORROSION, 70 (2014) 915927.

[9] Y. Wang, J.A. Wharton, R.A. Shenoi, Ultimate strength assessment of steel stiffened plate structures with grooving corrosion damage, Engineering Structures, 94 (2015) 29-42.

[10] S. Sultana, Y. Wang, A.J. Sobey, J.A. Wharton, R.A. Shenoi, Influence of corrosion on the ultimate compressive strength of steel plates and stiffened panels, Thin-Walled Structures, 96 (2015) 95-104.

[11] S. Saad-Eldeen, Y. Garbatov, C. Guedes Soares, Effect of corrosion severity on the ultimate strength of a steel box girder, Engineering Structures, 49 (2013) 560-571.

[12] Y. Garbatov, S. Saad-Eldeen, C. Guedes Soares, Hull girder ultimate strength assessment based on experimental results and the dimensional theory, Engineering Structures, 100 (2015) 742750.

[13] E. Gucuyen, R.T. Erdem, Corrosion effects on structural behaviour of jacket type offshore structures, Gradevinar, 66 (2014) 981-986.

[14] M. Hairil Mohd, B.J. Lee, Y. Cui, J.K. Paik, Residual strength of corroded subsea pipelines subject to combined internal pressure and bending moment, Ships and Offshore Structures, 10 (2016) 554-564.

[15] D.K. Kim, H.B. Kim, X. Zhang, C. Li, J.K. Paik, Ultimate stregnth performance of tankers associated with industry corrosion addition practices, International Journal of Naval Architeture and Ocean Engineering, 6 (2014) 507-528.

[16] J.K. Paik, S.K. Kim, S.K. Lee, Probabilistic corrosion rate estimation model for longitudinal strength members of bulk carriers, Ocean Engineering, 25 (1998) 837-860.

[17] Y. Bai, Y. Kim, H. Yan, X. Song, H. Jiang, Reassessment of the jacket structure due to uniform corrosion damage, Ships and Offshore Structures, 11 (2016) 105-112.

[18] D. Gao, G. Shi, D. Wang, Residual ultiamte strength of hull structures with crack and corrosion damage, Engineering Failure Analysis, 25 (2012) 316-328.

[19] D.K. Kim, M.S. Liew, S.A.M. Youssef, M. Hairil Mohd, H.B. Kim, J.K. Paik, Time-dependent ultimate strength performance of corroded FPSOs, Arabian Journal for Science and Engineering, 39 (2014) 7673-7690.

[20] X. Jiang, C. Guedes Soares, Ultimate capacity of rectangular plates with partial depth pits under uniaxial loads, Marine Structures, 26 (2012) 27-41.

[21] ISSC, Report of Specialist Committee III.1 Ultimate Strength, in: Proceedings of the 17th International Ship and Offshore Structures Congress, Seoul, Korea, 2009, pp. 375-474.

[22] C. Shi, H. Karagah, M. Dawood, A. Belarbi, Numerical investigation of H-shaped short steel piles with localized severe corrosion, Engineering Structures, 73 (2014) 114-124.

[23] R.M. Pidaparti, A.S. Rao, Analysis of pits induced stresses due to metal corrosion, Corrosion Science, 50 (2008) 1932-1938.

[24] M. Ahmmad, Y. Sumi, Strength and deformability of corroded steel plates under quasi-static tensile load, Journal of Marine Science and Technology, 15 (2010) 1-15.

[25] S. Kainuma, Y. Jeong, J. Ahn, T. Yamagami, S. Tsukamoto, Behavior and stress of orthotropic deck with bulb rib by surface corrosion, Journal of Constructional Steel Research, 113 (2015) 135145.

[26] DNVGL, DNVGL-CG-0127 Finite Element Analysis, in: Class Guidance, 2015.

[27] Lloyd's Register, Fatigue Design Assessment, in: ShipRight Design and Construction, 2009.

[28] J. Harwood, The influence of stress on corrosion, Corrosion, 6 (1950) 249-259.

[29] K. Nobe, S. Tan, Electrical Potential Responses of Silver, Steel and Brass Stressed in Tension In Sodium Chloride Solutions, Corrosion, 18 (1962) 391t-395t.

[30] E.M. Gutman, Mechanochemistry of solid surfaces, World Scientific Publishing Co. Pte. Ltd., Singapore, 1994. 
[31] Y. Wang, W. Zhao, H. Ai, X. Zhou, T. Zhang, Effects of strain on the corrosion behaviour of X80 steel, Corrosion Science, 53 (2011) 2761-2766.

[32] A.R. Despic, R.G. Raicheff, J.O.M. Bockris, Mechanism of the acceleration of the electrodic dissolution of metals during yielding under stress, The Journal of Chemical Physics, 49 (1968) 926938.

[33] L.Y. Xu, Y.F. Cheng, An experimental investigation of corrosion of X100 pipeline steel under uniaxial elastic stress in a near-neutral pH solution, Corrosion Science, 59 (2012) 103-109.

[34] S. Zhang, X. Pang, Y. Wang, K. Gao, Corrosion behavior of steel with different microstructures under various elastic loading conditions, Corrosion Science, 75 (2013) 293-299.

[35] Z.Y. Liu, X.G. Li, Y.F. Cheng, Effect of strain rate on cathodic reaction during stress corrosion cracking of X70 pipeline steel in a near-neutral pH solution, Journal of Materials Engineering and Performance, 20 (2011) 1242-1246.

[36] H.Q. Yang, Q. Zhang, S.S. Tu, Y. Wang, Y.M. Li, Y. Huang, Effects of inhomogeneous elastic stress on corrosion behaviour of Q235 steel in $3.5 \% \mathrm{NaCl}$ solution using a novel multi-channel electrode technique, Corrosion Science, 110 (2016) 1-14.

[37] Y. Wang, J.A. Wharton, J. Downes, R.A. Shenoi, Marine structural integrity subject to mechano-electrochemical induced corrosion, in: NACE CORROSION 2017 Conference and Expo, New Orleans, US, 2017.

[38] L.Y. Xu, Y.F. Cheng, Development of a finite element model for simulation and prediction of mechanoelectrochemical effect of pipeline corrosion, Corrosion Science, 73 (2013) 150-160.

[39] Y. Wang, J.A. Wharton, R.A. Shenoi, Mechano-electrochemical modelling of corroded steel structures, Engineering Structures, 128 (2016) 1-14.

[40] J.K. Paik, D.K. Kim, Advanced method for the development of an empirical model to predict time-dependent corrosion wastage, Corrosion Science, 63 (2012) 51-58.

[41] Y. Garbatov, C. Guedes Soares, Corrosion wastage statistics and maintenance planning of corroded hull structures of bulk carriers, in: C. Guedes Soares, P.K. Das (Eds.) Analysis and Design of Marine Structures, Taylor \& Francis Group, London, UK, 2009.

[42] J. Ahn, S. Kainuma, F. Yasuo, I. Takehiro, Repair method and residual bearing strength evaluation of a locally corroded plate girder at support, Engineering Failure Analysis, 33 (2013) 398418.

[43] N. Khurram, E. Sasaki, U. Akmal, M.U. Saleem, M.N. Amin, A comparative study in utilizing the shell and solid elements formulation for local corrosion simulation at bearing stiffener, Arabian Journal for Science and Engineering, (2016).

[44] G. Crammond, S.W. Boyd, J.M. Dulieu-Barton, Evaluating the localised through-thickness load transfer and damage initiation in a composite joint using digital image correlation, Composite: Part A, 61 (2014) 224-234.

[45] J. Kovac, T.J. Marrow, E. Govekar, A. Legat, Detection and characterisation of intergranular stress-corrosion cracking on austenitic stainless steel, Materials and Corrosion, 63 (2012) 664-673.

[46] H. Ghadbeigi, C. Pinna, S. Celotto, Quantitative strain analysis of the large deformation at the scale of microstructure: comparison between digital image correlation and microgrid techniques, Experimental Mechanics, 52 (2012) 1483-1492.

[47] V. Savic, L.G. Hector, J.R. Fekete, Digital image correlatino study of plastic deformation and fracture in fully martensitic steels, Experimental Mechanics, 50 (2010) 99-110.

[48] H. Karagah, C. Shi, M. Dawood, A. Belarbi, Experimental investigationofshortsteelcolumnswith localised corrosion, Thin-Walled Structures, 87 (2015) 191199.

[49] M.A. Sutton, J. Orteu, H.W. Schreier, Image correlation for shape, motion and deformation measurements, Springer Science+Business Media, LLC, New York, 2009.

[50] LaVision, DaVis 8.0 Software product manual, (2012).

[51] T. Hutt, P. Cawley, Feasibility of digital image correlation for detection of cracks at fastener holes, NDT\&E International, 42 (2009) 141-149. 
[52] D.A. Crump, J.M. Dulieu-Barton, J. Savage, Design and commission of an experimental test rig to apply a full-scale pressure load on composite sandwich panels representative of an aircraft secondary structure, Measurement Science and Technology, 21 (2010).

[53] Abaqus, Abaqus 6.14 Documentation, in, Dassault Systèmes, 2014.

[54] C.S. Smith, P.C. Davidson, J.C. Chapman, P.J. Dowling, Strength and stiffness of ships' plating under in-plane compression and tension, RINA, Trans., 130 (1988) 277-296.

[55] M.A. Crisfield, A fast incremental/iteration solution procedure that handles 'snap-through', Computers and Structures, 13 (1981) 55-62.

[56] ISSC, Report of Specialist Committee III.1 Ultimate Strength, in: Proceedings of the 19th International Ship and Offshore Structures Congress, Cascais, Portugal, 2015, pp. 280-349. 
Table 1. DIC and deck plate model properties

\begin{tabular}{|c|c|c|}
\hline Model Properties & DIC specimens & Deck plate \\
\hline$a / \mathrm{mm}$ & 90 & 3900 \\
\hline $\mathrm{b} / \mathrm{mm}$ & 90 & 830 \\
\hline$t_{p} / \mathrm{mm}$ & 3 & 8 \\
\hline Young's modulus E / GPa & 205 & 205.8 \\
\hline Yield stress $\sigma_{\mathrm{y}} / \mathrm{MPa}$ & 520 & 315 \\
\hline Poisson ratio $v$ & 0.3 & 0.3 \\
\hline Tangent modulus $E_{t} / G P a$ & 0 & 0 \\
\hline plate slenderness ratio $\boldsymbol{\beta}$ & 2.472 & 4.059 \\
\hline Element types & $\begin{array}{l}\text { S4R with enhanced } \\
\text { hourglass control }\end{array}$ & $\begin{array}{l}\text { S4R with and without } \\
\text { enhanced hourglass control, } \\
\text { C3D8R and C3D8R with } \\
\text { enhanced hourglass control, } \\
\text { C3D20, C3D20R, C3D10I }\end{array}$ \\
\hline
\end{tabular}



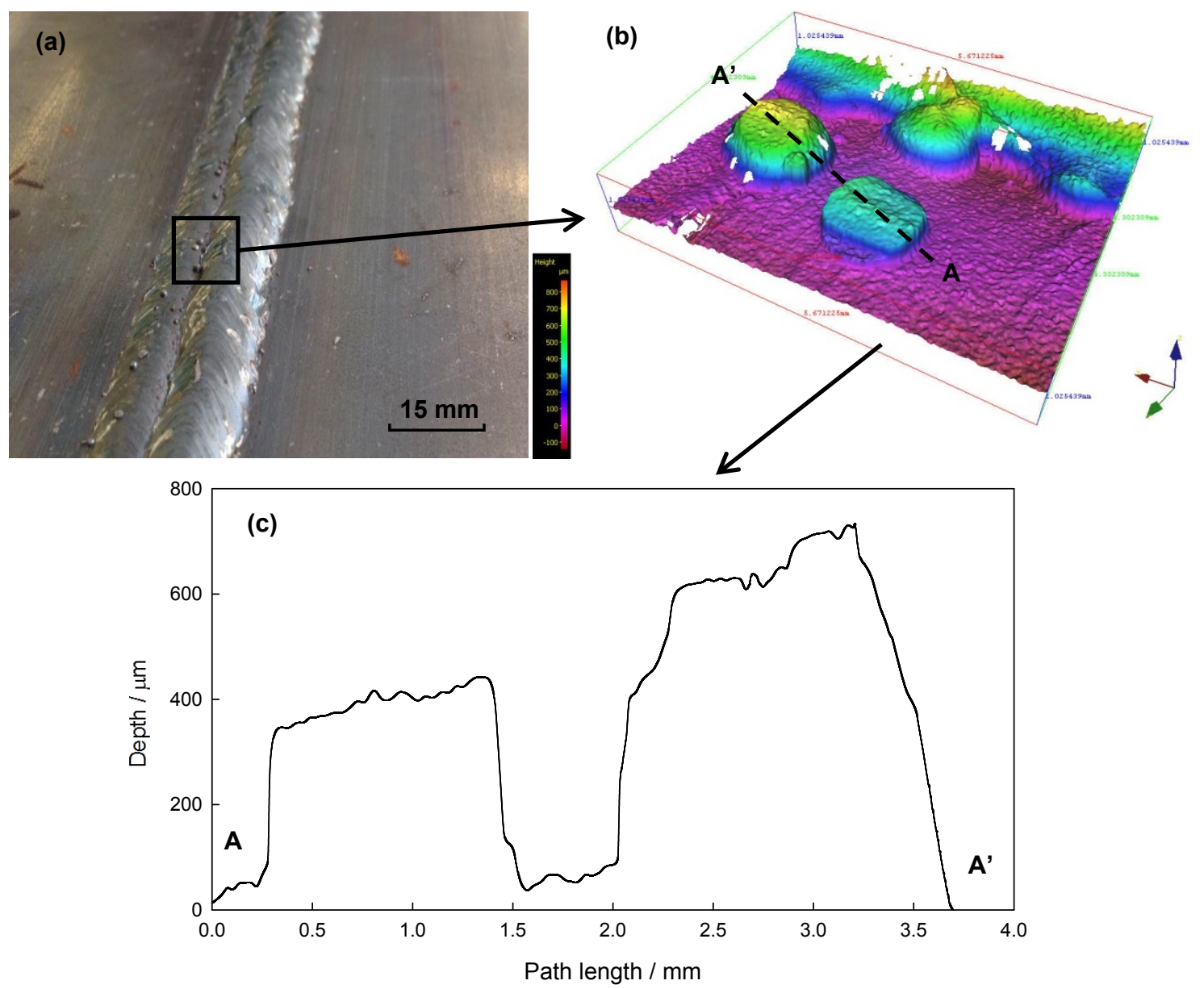

Figure 1: Imperfections on the butt welds of a shipping grade steel plate: (a) welded plate sample; (b) threedimensional surface profilometry (scan area: $5.7 \mathrm{~mm} \times 4.3 \mathrm{~mm}$ ); and (c) profile between $A-A^{\prime}$. 


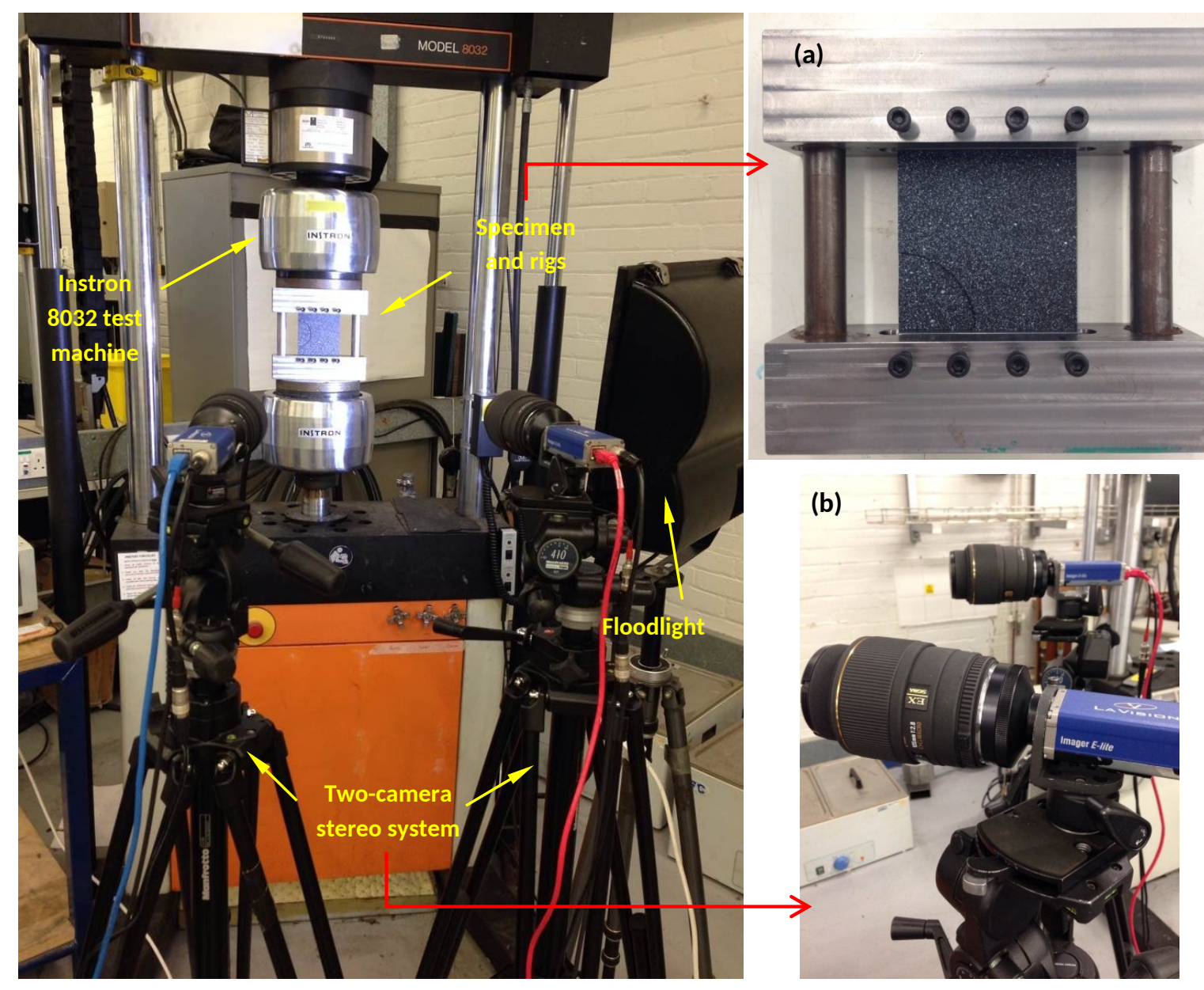

Figure 2: 3D DIC experimental set-up: (a) specimen and rigs; (b) a 3D camera system including two Sigma 105 $\mathrm{mm}$ lenses and two 5 MP 12 bit monochromatic LaVision E-lite CCD cameras. 

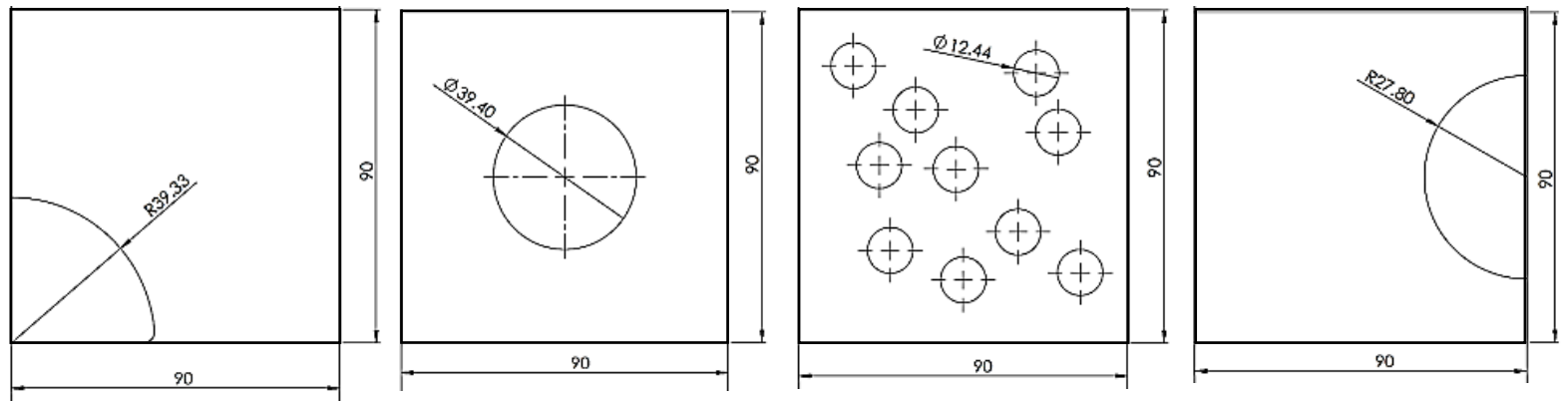

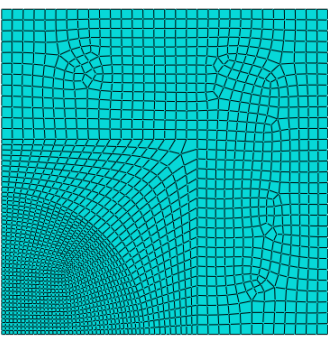

(a)

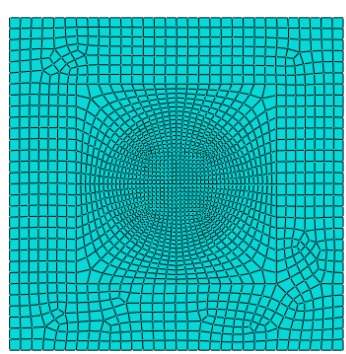

(b)

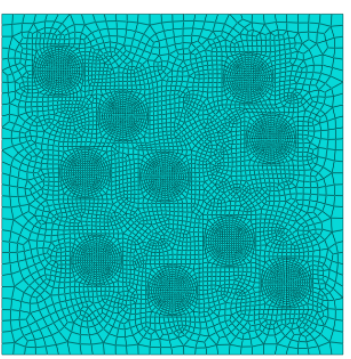

(c)

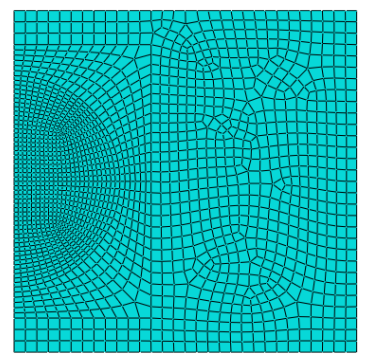

(d)

Figure 3: 3D DIC specimens and mesh patterns (dimensions in $\mathrm{mm}$ ): (a) corrosion at the corner; (b) corrosion in the middle; $(c)$ random pitting; and (d) corrosion at the unloaded edge. 


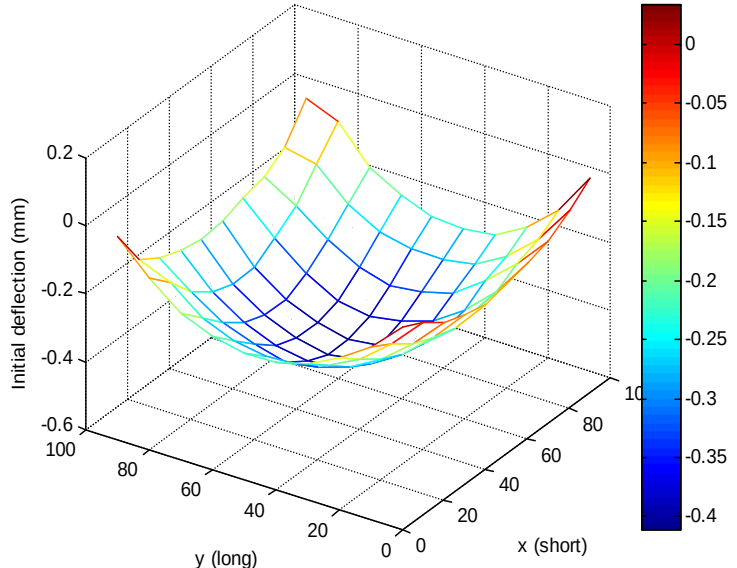

(a)

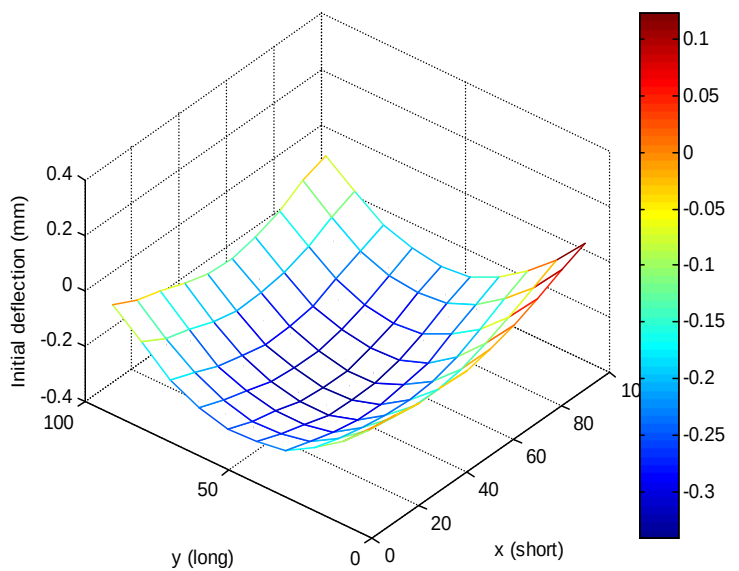

(c)

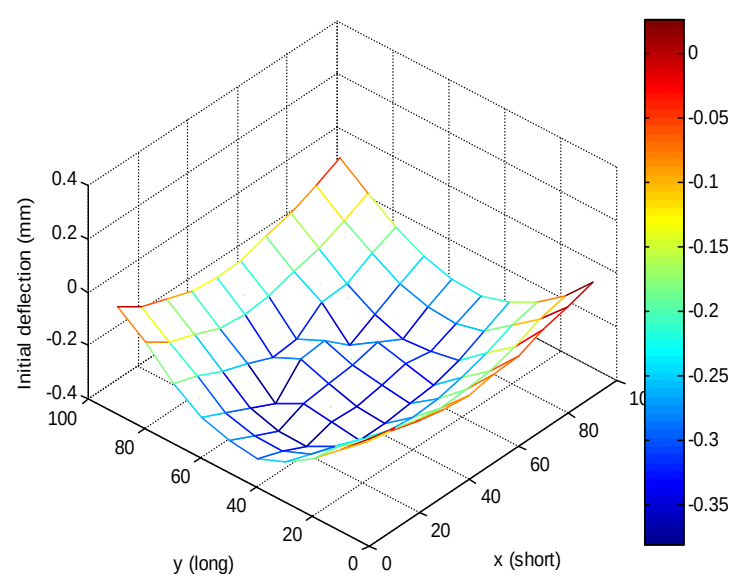

(b)

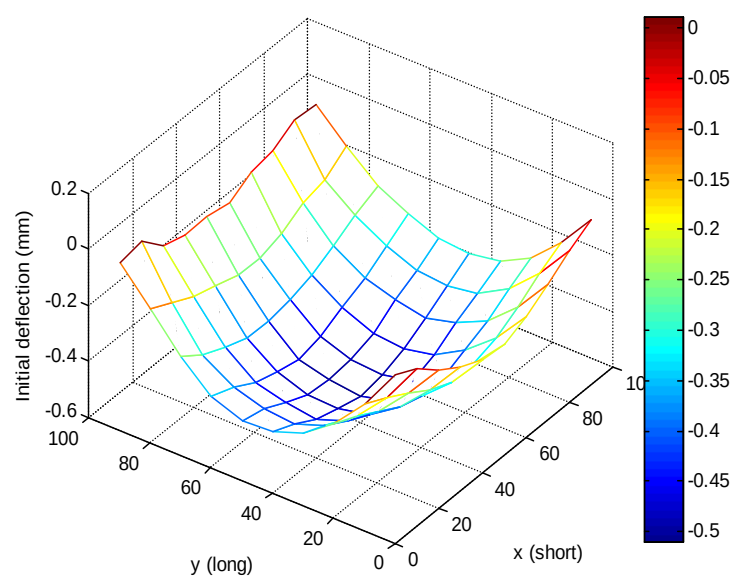

(d)

Figure 4: Initial deflections measured at discrete locations using Faro Arm: (a) corrosion at the corner; (b) corrosion in the middle; (c) random pitting; (d) corrosion at the unloaded edge. 


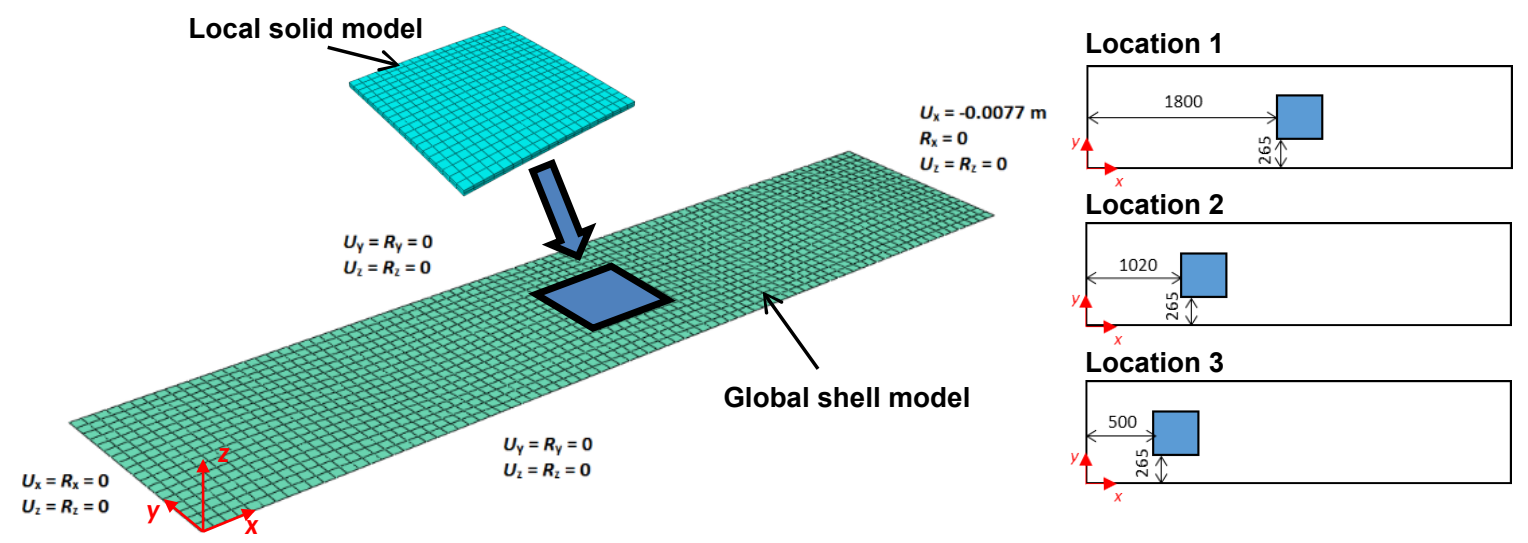

Figure 5. Boundary conditions of the deck plate model (distance values are in $\mathrm{mm}$ ). 


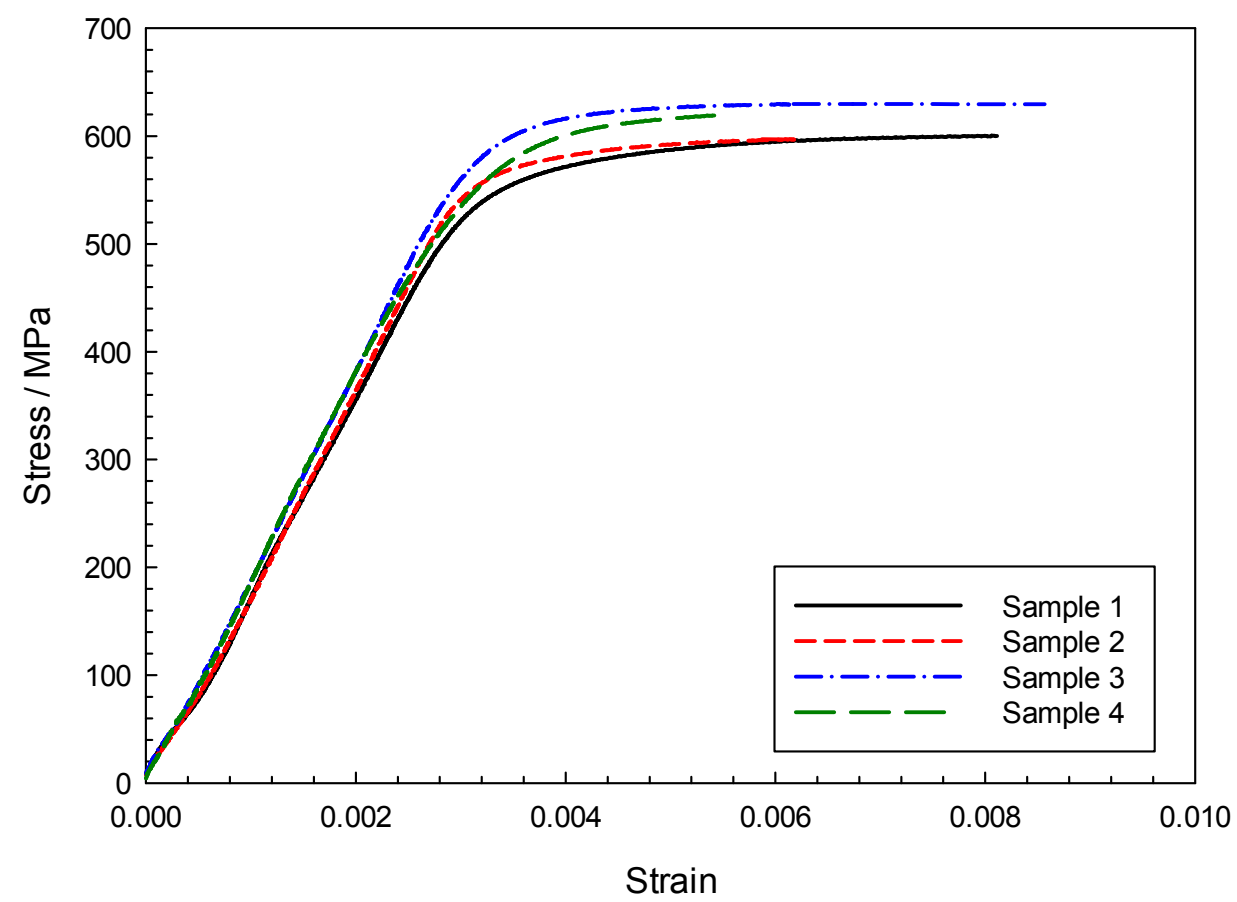

Figure 6: Stress-strain relationships of DIC samples from tensile tests. 


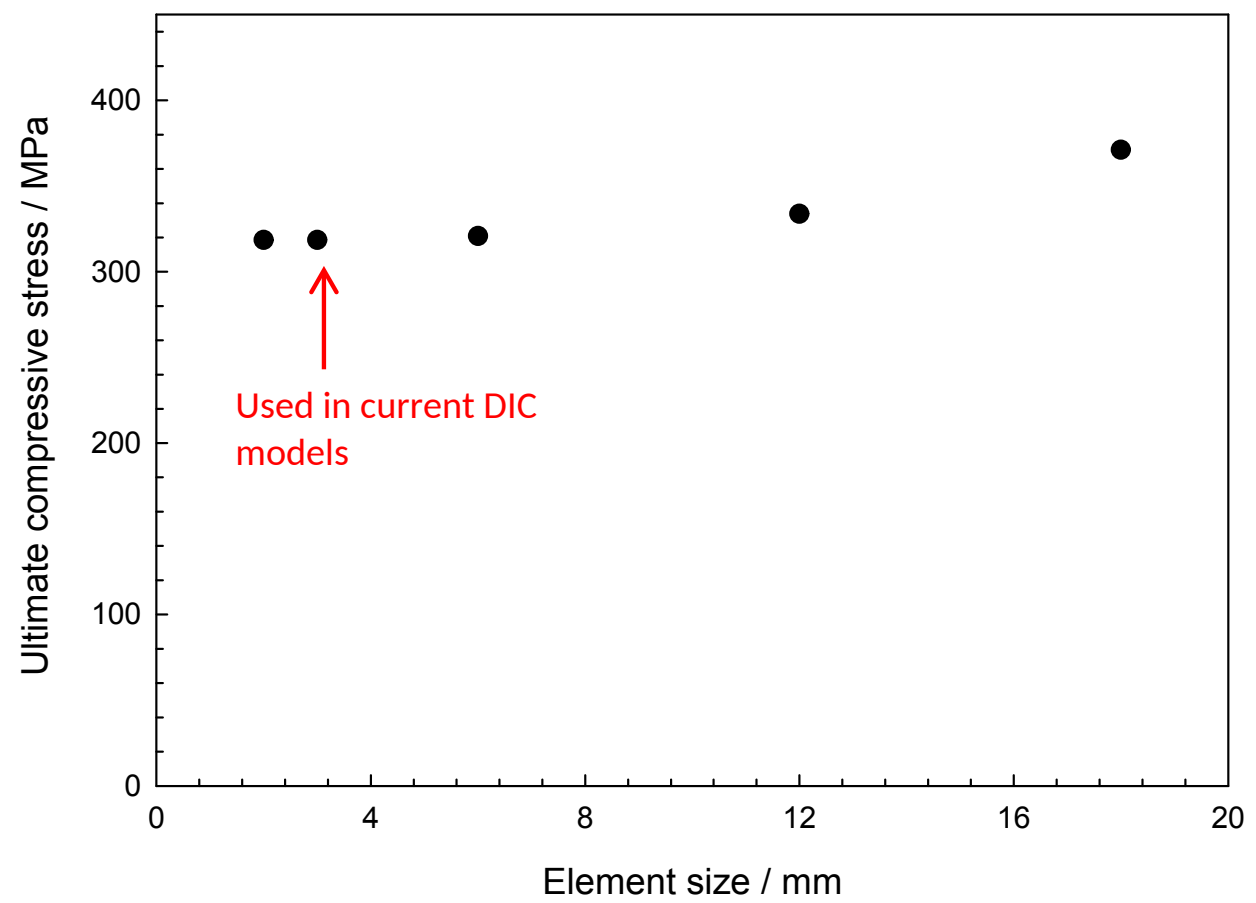

(a)

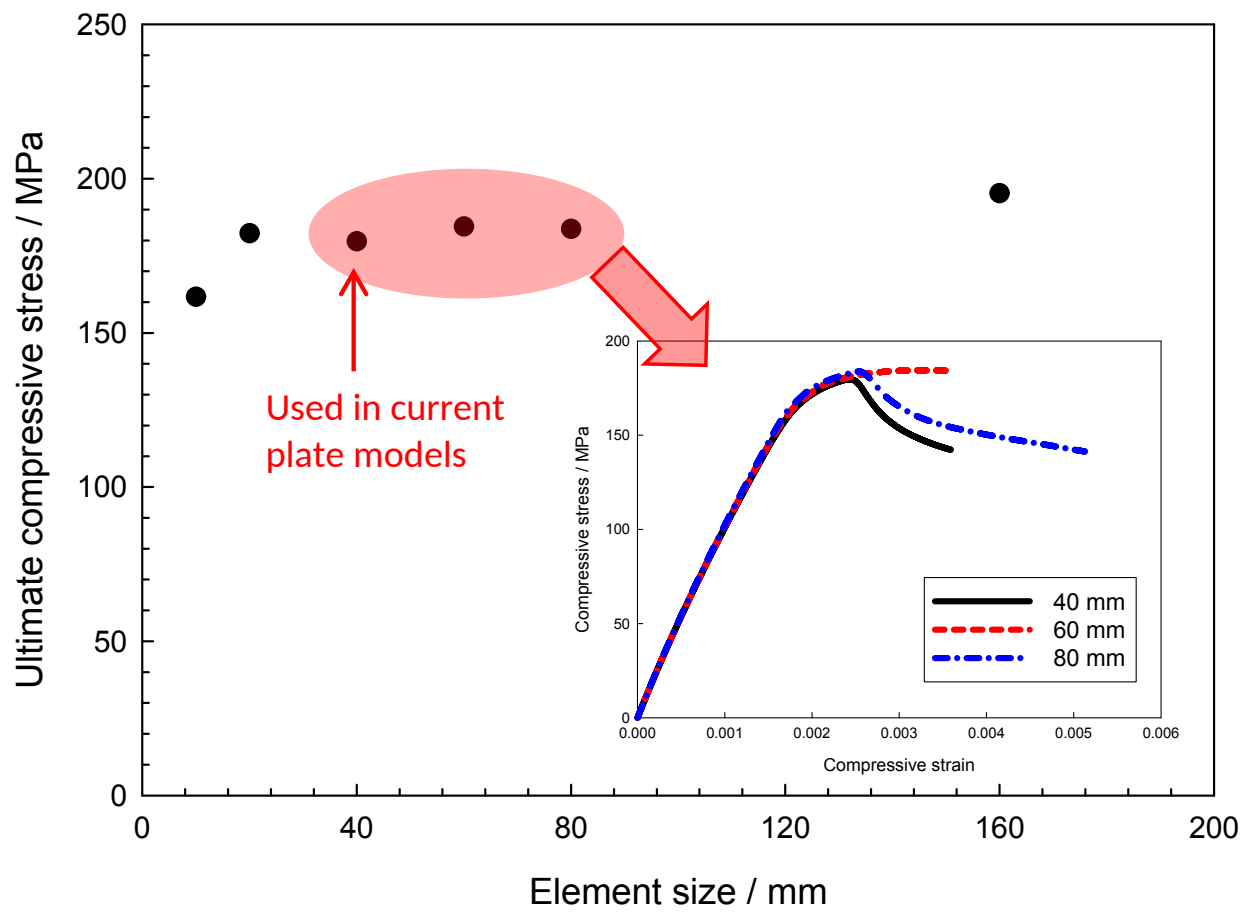

(b)

Figure 7: Mesh convergence study; the element size is the typical values used along the plate edges: (a) DIC sample with random pitting; (b) deck plate using shell element S4R. 
(a) Left corner corrosion

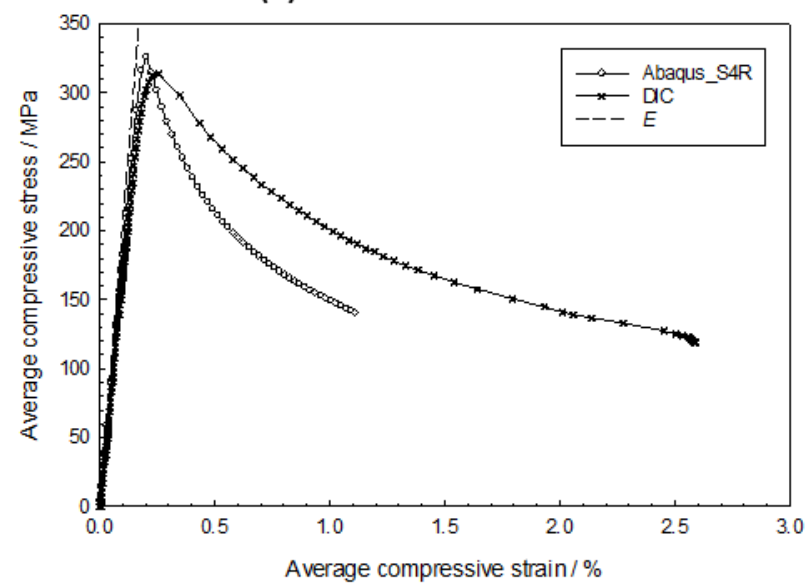

(c) Random pitting

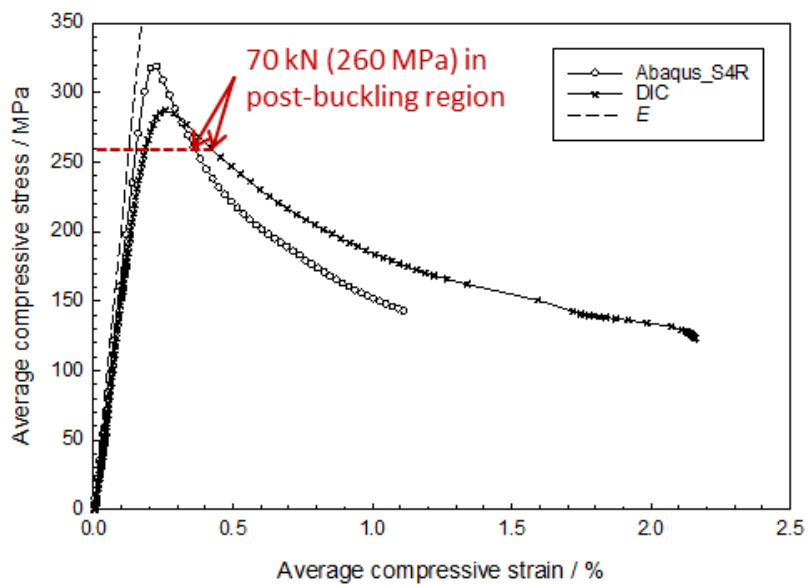

(b) Middle corrosion

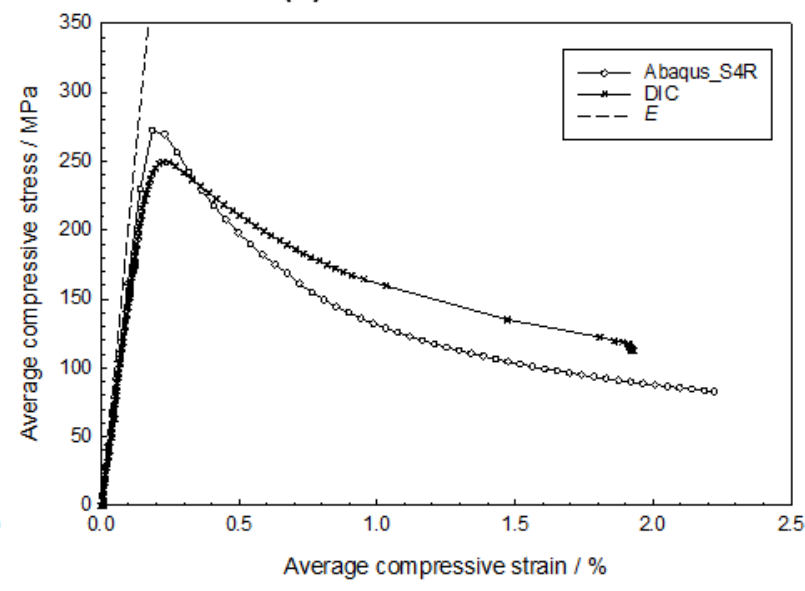

(d) Corrosion on unloaded edge

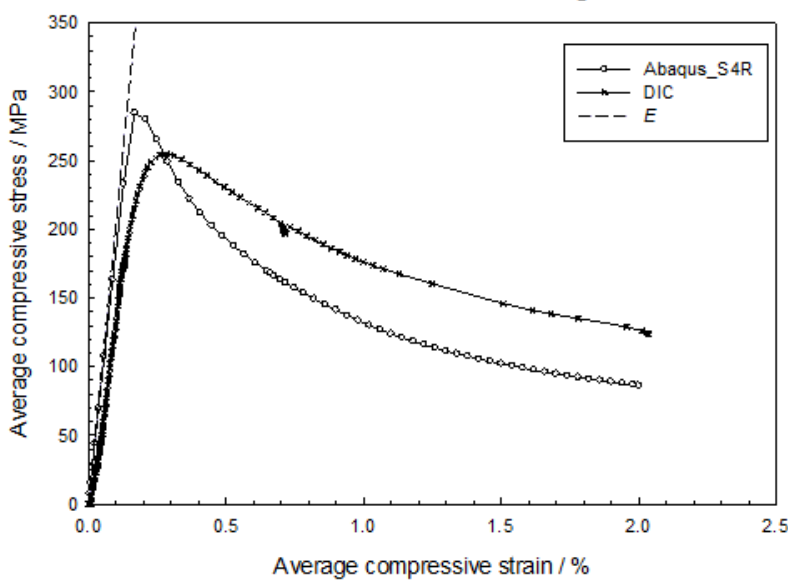

Figure 8. Average compressive stress-strain relationships obtained from DIC and FEA models, simulating (a) corrosion at the corner of the plate; (b) corrosion in the centre; (c) random pitting; (d) corrosion at the unloaded edge. The dotted line represent the Young's modulus $E$ of the material. 


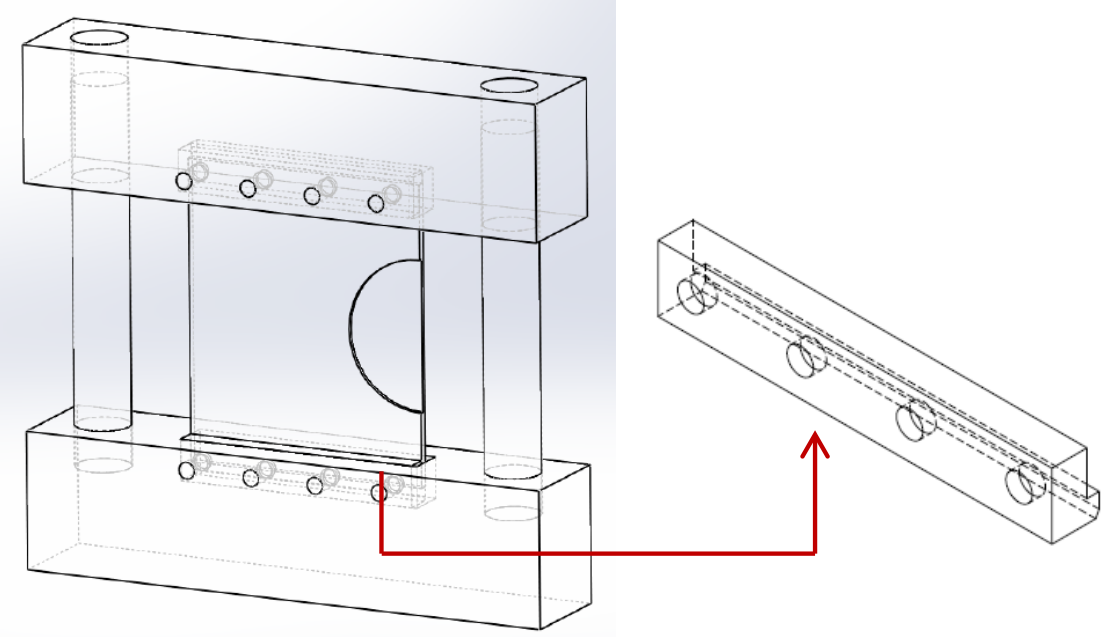

Figure 9. Schematic of a DIC specimen and the rigs (tested area of the specimen: $90 \mathrm{~mm} \times 90 \mathrm{~mm} \times 3 \mathrm{~mm}$ ). 


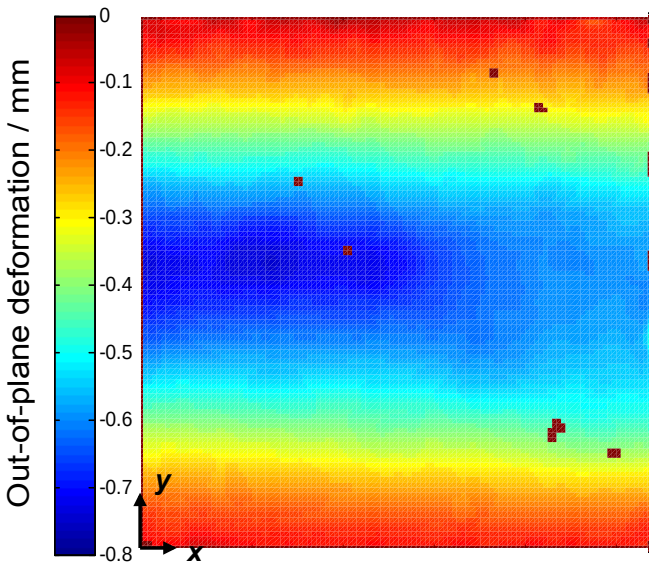

(a)

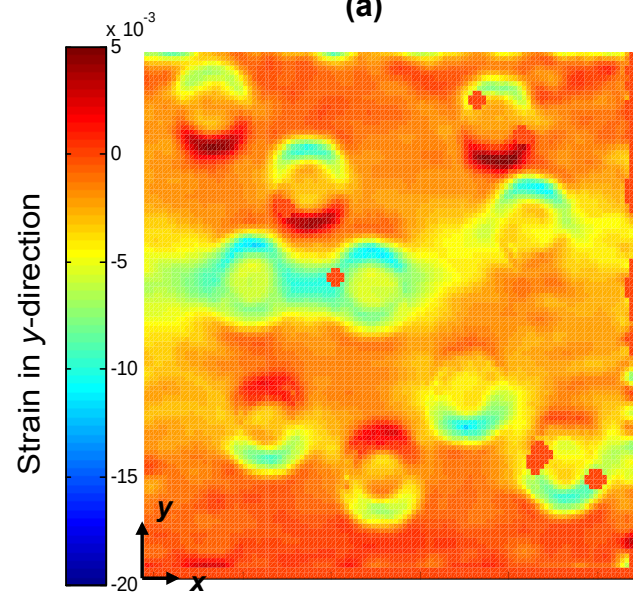

(c)

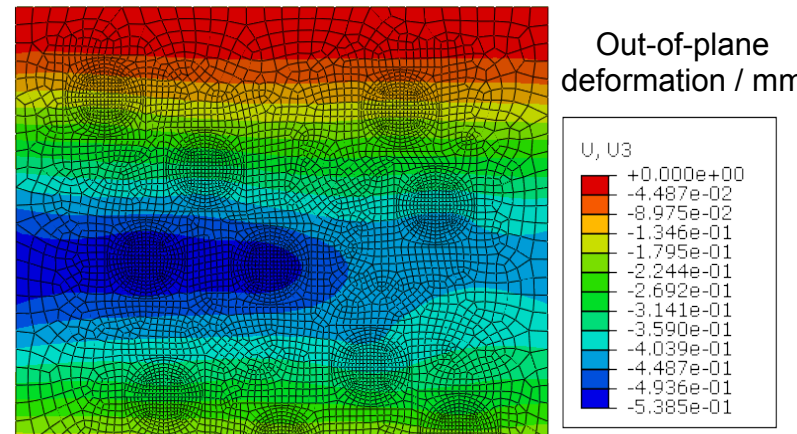

(b)

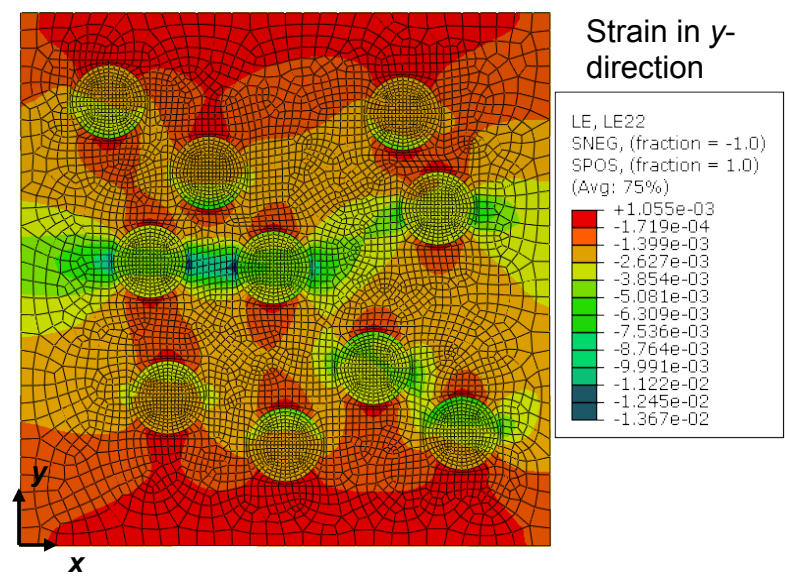

(d)

Figure 10. Contour plots for random pitting condition at ultimate strength: (a) out-of-plane deformation from DIC; (b) out-of-plane deformation from FEA; (c) in-plane strain from DIC; and (d) in-plane strain from FEA. 


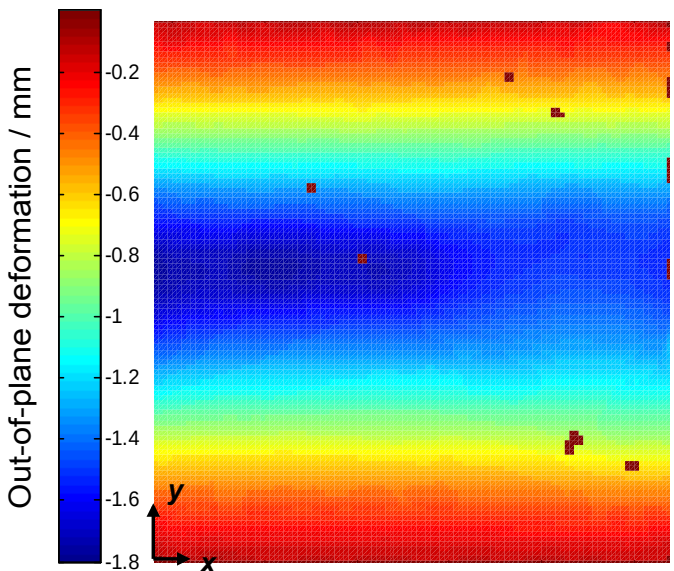

(a)

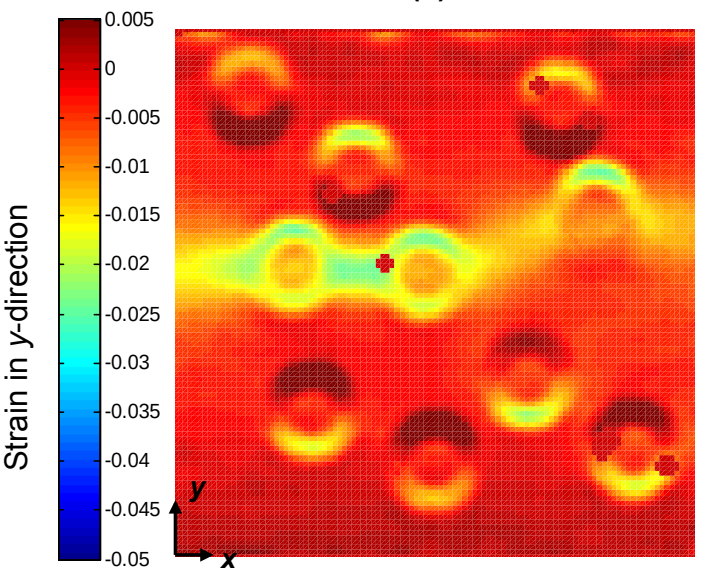

(c)

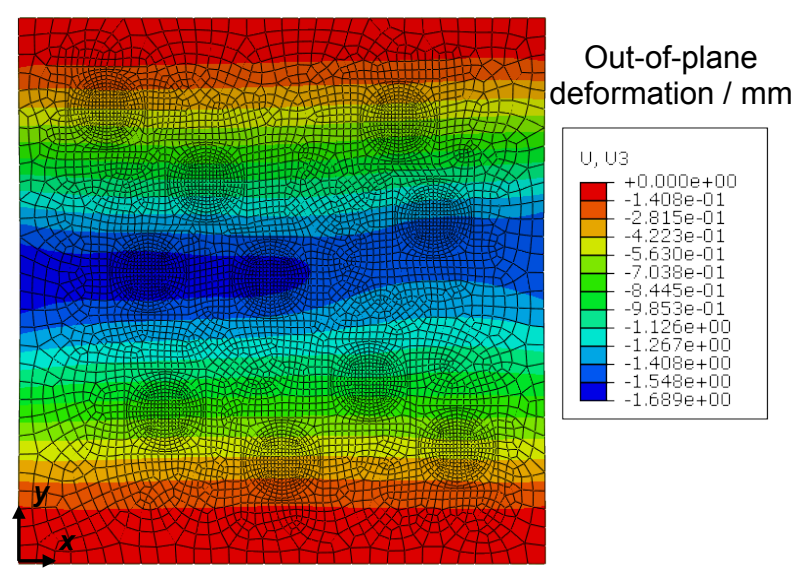

(b)

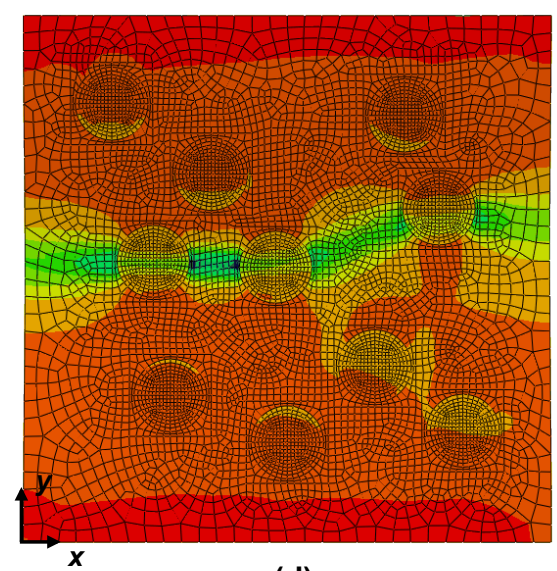

(d)
Strain in $y$ direction

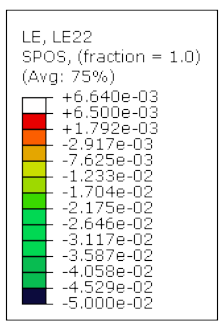

Figure 11. Contour plots for random pitting condition at post-buckling region (indicated in Figure 5 (c)): (a) out-of-plane deformation from DIC; (b) out-of-plane deformation from FEA; (c) in-plane strain from DIC; and (d) in-plane strain from FEA. 


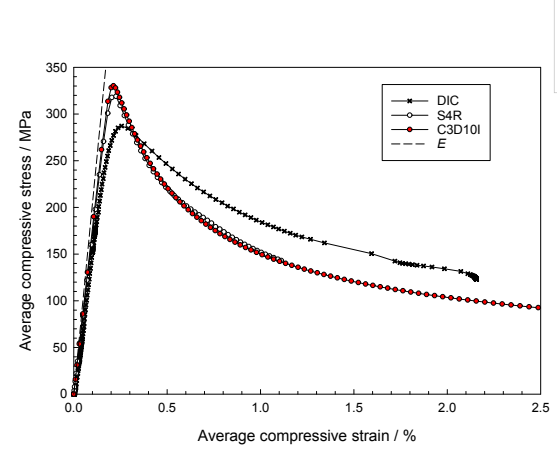

(a)

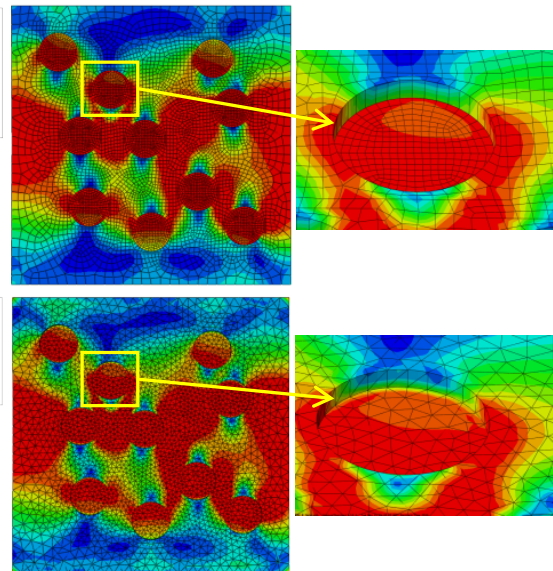

Figure 12. An example of the comparison between shell and solid element models for DIC specimens: (a) average compressive stress-strain curves; (b) von Mises stress contour plot for shell element S4R; and (c) von Mises stress contour plot for solid element C3D10I. 


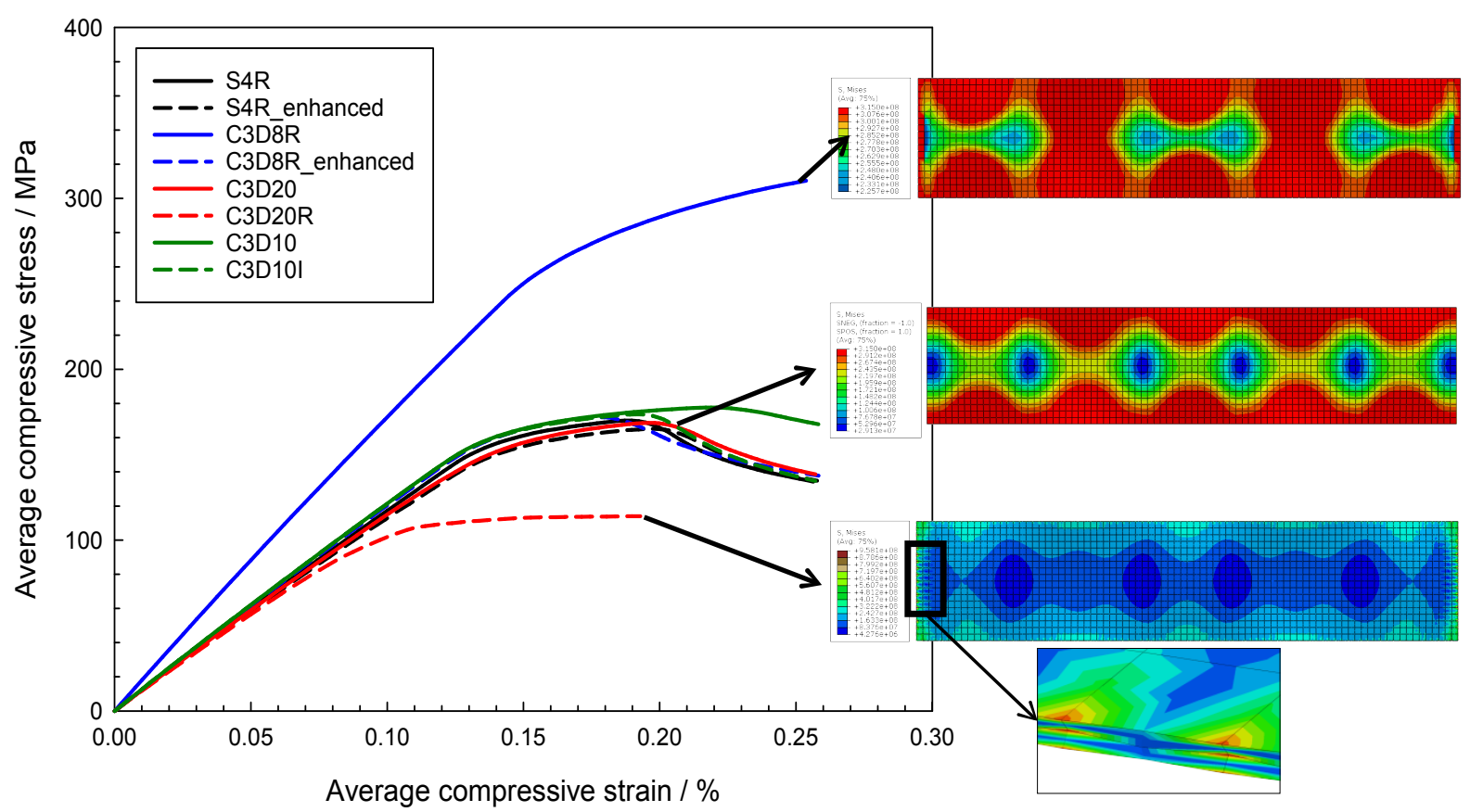

Figure 13. Comparison of the average compressive stress-strain curves for the deck plate model using either shell or solid elements (enhanced: enhanced hourglass control). Contour plots are von Mises stress distributions at the model's ultimate strength. 


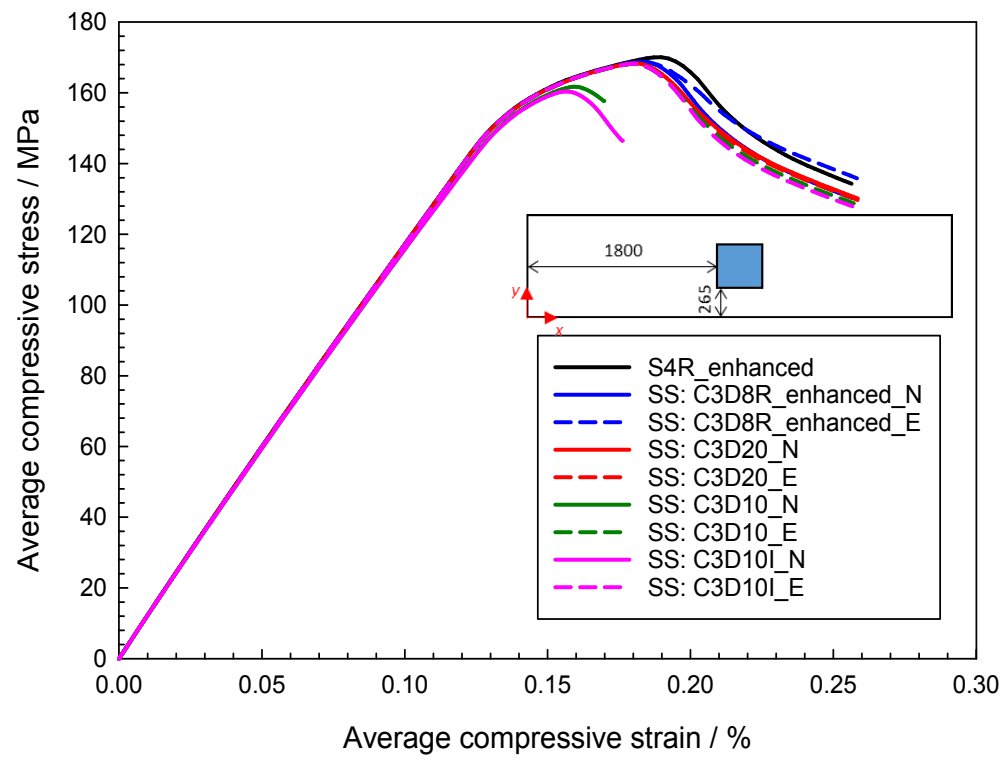

Figure 14. Comparison between node-based and surface-based solid elements for shell-solid coupling models (solid model is located in the centre of the deck plate). 


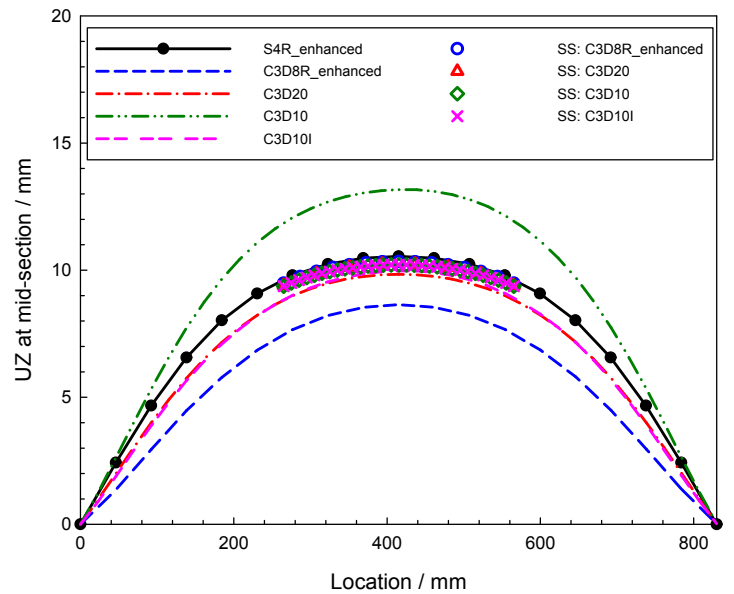

(a)

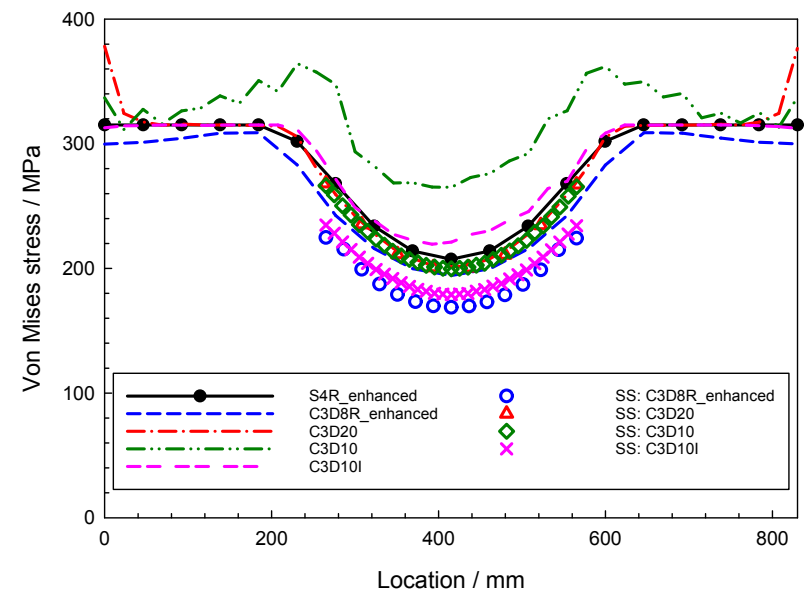

(b)

Figure 15. Local solid model mid-width line (along y-direction) results at ultimate strength: (a) out-of-plane deformation UZ; and (b) von Mises stress (element-based Shell-Solid (SS) models). 


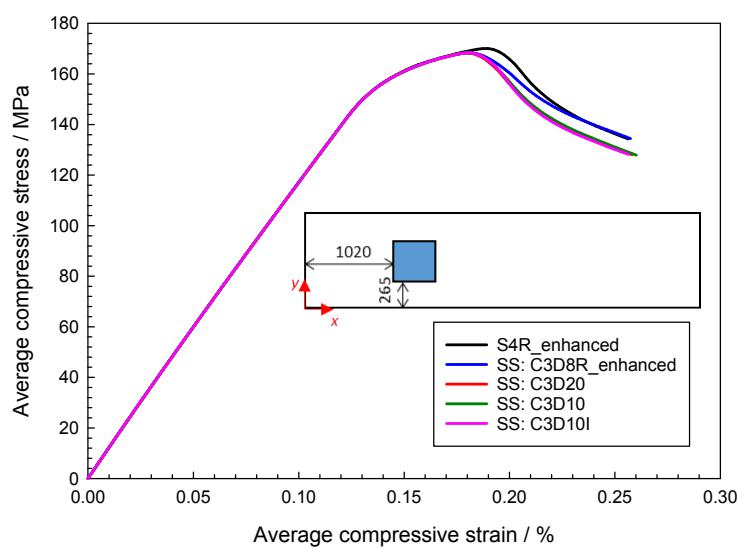

(a)

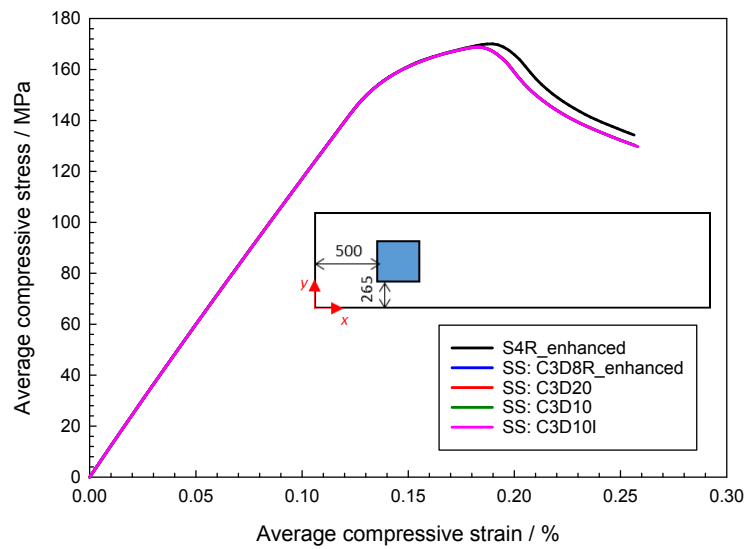

(b)

Figure 16. Element-based shell-solid coupling results for different solid model locations: (a) Location 2; and (b) Location 3. 

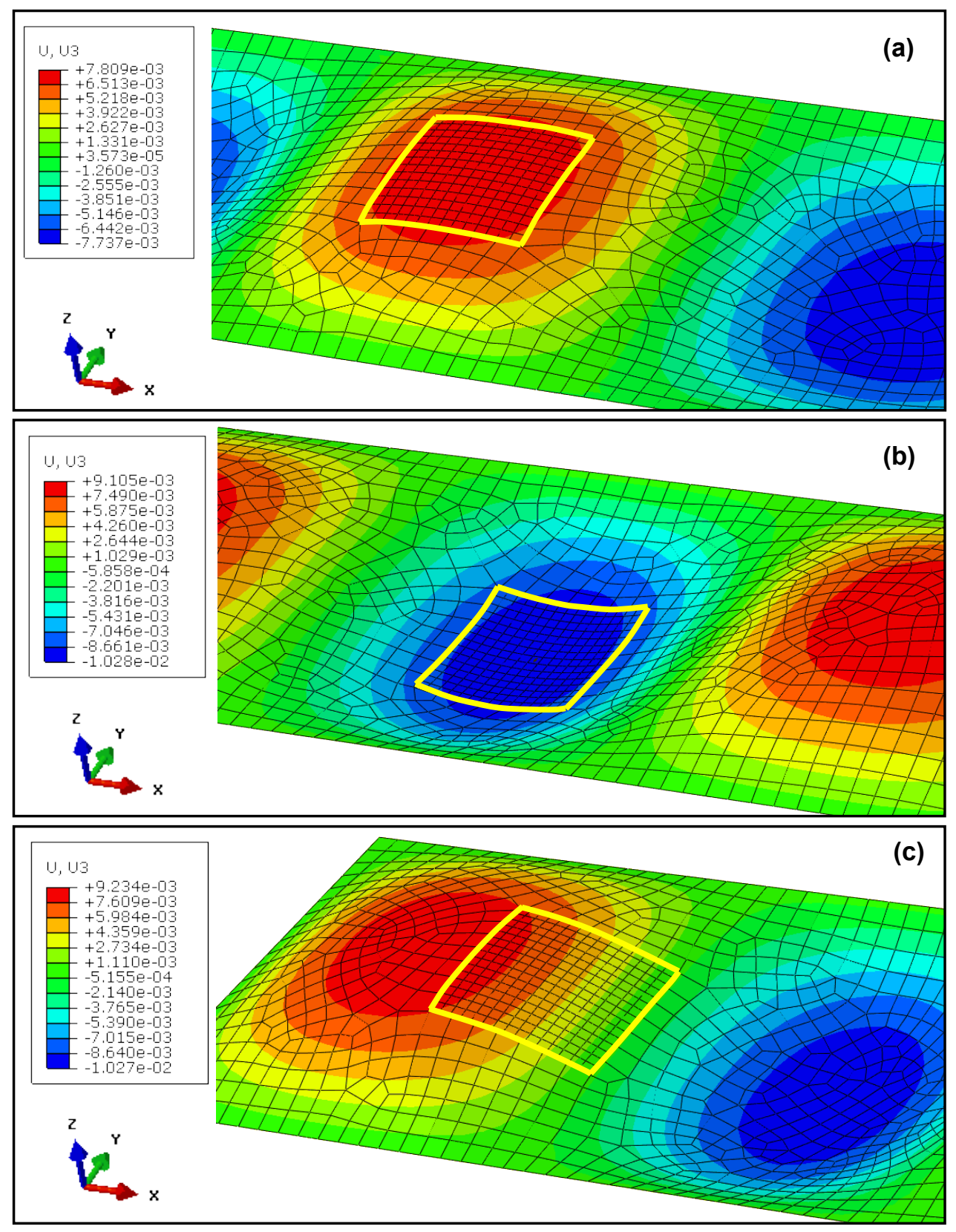

Figure 17. Out-of-plane displacement (mm) at the ultimate strength state for (a) Location 1; (b) Location 2; (c) Location 3. The area within the yellow box is the solid model. 